\author{
By \\ Noah Kenneally \\ B.A. Honours, Ryerson University, 2012 \\ A Major Research Paper \\ Presented to Ryerson University \\ In partial fulfillment of the requirements for the degree of \\ Master of Arts \\ In the Program of \\ Early Childhood Studies
}

Toronto, Ontario, Canada, 2013

(C) Noah Kenneally, 2013 


\section{Author's Declaration}

I hereby declare that I am the sole author of this MRP. This is a true copy of the MRP, including any required final revisions.

I authorize Ryerson University to lend this MRP to other institutions or individuals for the purpose of scholarly research.

I further authorize Ryerson University to reproduce this MRP by photocopying or by other means, in total or in part, at the request of the other institutions or individuals for the purpose of scholarly research.

I understand that my MRP may be made electronically available to the public. 


\title{
CHILDREN AND INQUIRY: RESEARCHERS' REFLECTIONS ON RESEARCH INVOLVING CHILDREN
}

\author{
(C) Noah Kenneally, 2013 \\ Master of Arts Early Childhood Studies \\ Ryerson University
}

\begin{abstract}
This qualitative descriptive study employed a mixed methods approach to investigate research conducted by Canadian researchers who involve children in their studies. Data collected from a questionnaire completed by thirty researchers across Canada were contextualized through seven interviews, with the goal of compiling a description of the research designs and the mechanisms of engagement used to involve children. A thematic analysis was conducted in order to explore the research designs used, how beliefs about children and childhood shape research design, and ethical and reflective practices used in research involving children. Overall, findings indicate that a wide range of research designs and mechanisms of engagement are used. Implications for practice emerging from this study suggest that researchers should choose a design approach to best suit the study's purpose, and that deliberate and continuous reflection in design practices and implementation can promote ethical practice when conducting research involving children.
\end{abstract}

Key Words: Research Involving Children; Research Design; Researchers' Perspectives; Reflective Practice; Ethical Practice; Data Collection Methods; Canada. 


\section{Acknowledgements}

I would like to take this opportunity to thank the researchers who participated in this study, who were incredibly generous with their time and in sharing their experiences with me. Without their participation and encouragement, this research study would not have been possible. It is by engaging with their voices and experiences that I hope to demonstrate that the Canadian landscape of research involving children is vibrant, varied and thriving.

I would like to express my profound thanks to my supervisor Dr. Aurelia Di Santo for her continuous support through this process, for the pivotal sharing of perspectives and for untold hours and pages of critical and helpful feedback. Her knowledge of the field of social research with children and her commitment to quality research were instrumental to the success of this research study. I would also like to thank Dr. Jason Nolan, the second reader of this study, for not only taking that role but for supporting my initial questions that lay at the heart of this project in our countless conversations. I would like to thank Dr. Mehrunissa Ali, the Chair of the Graduate Programme in Early Childhood Studies, for working to support a welcoming and engaging learning environment; and it is important that I also acknowledge the entire faculty of the School of Early Childhood Studies at Ryerson University, all of whom have contributed to my developing knowledge in the field of early childhood studies, and to whom I owe a profound debt for helping me find my current path.

I would also like to thank my cohort in MAECS, whose engaging and keen minds and supportive hearts were a tremendous part in creating a nurturing community of learners. It was a privilege to learn and grow with you. Look what we have done.

Finally, I am profoundly grateful to my parents and family for their unflagging enthusiasm and support, and my partner Sean, whose love and care keeps me grounded and who challenges me to keep my head aligned with my heart. 


\section{Table of Contents}

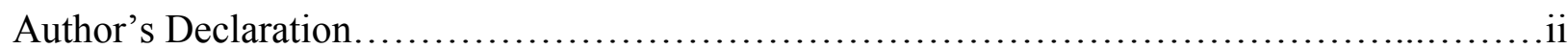

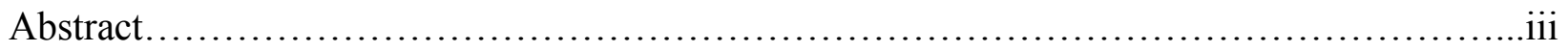

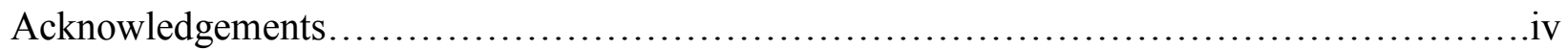

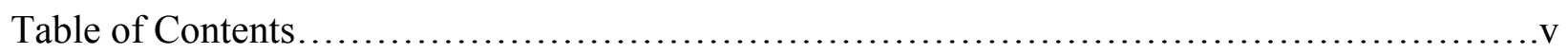

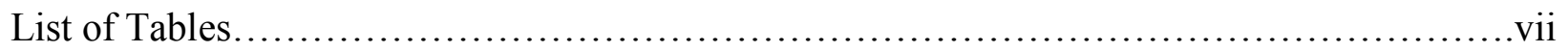

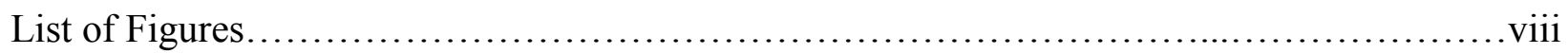

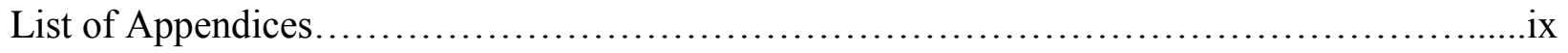

Chapter 1: Introduction............................................................

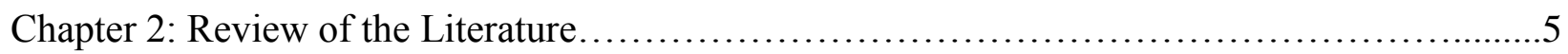

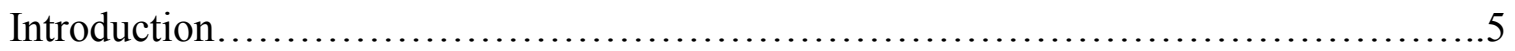

The Roles of Children in Research.............................................6

Conceptualizations of Children and their Influence on Research.......................10

Researchers Involving Children in Research..................................16

Chapter 3: Methods............................................................25

Methodological Approach and Rationale......................................25

Participants and Recruitment..............................................27

Data Measures and Collection.............................................29

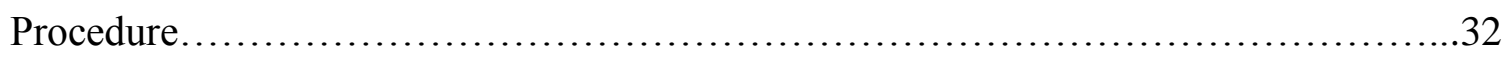

Data Organization......................................................... 33

Data Analysis......................................................... 33

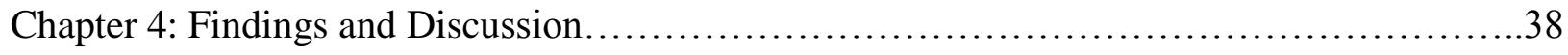

Mechanisms of Engagement................................................... 38 
Researchers' Experiences Involving Children In Research...........................43

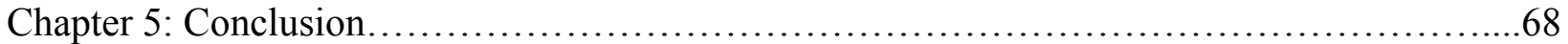

Implications for Practice.................................................68

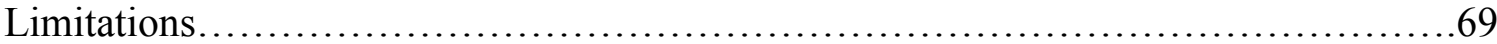

Recommendations for Future Research.....................................69

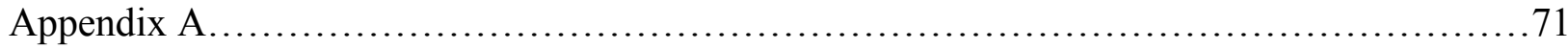

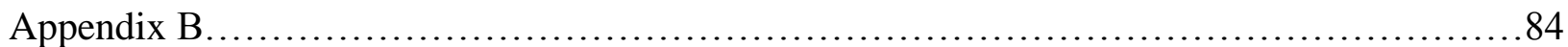

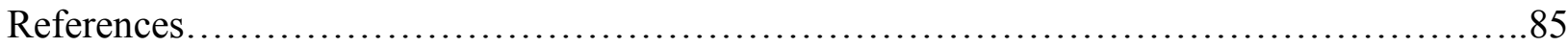




\section{List of Tables}

Table 1. Distribution of participants............................................... 33

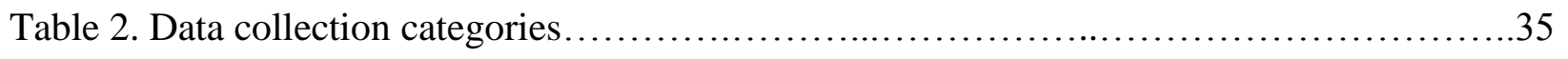

Table 3. Reported use of data collection categories and tools.............................42 


\section{List of Figures}

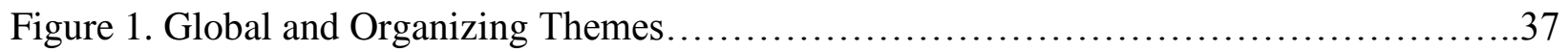




\section{List of Appendices}

Appendix A. Research Methods for Involving Children - Questionnaire.....................71

Appendix B. Semi-structured Interview Guide...................................84 


\section{Chapter 1: Introduction}

Issues of children and childhood have been the topic of research in a number of scholarly disciplines for centuries. Children's biological development has been examined and measured, their cognitive capabilities investigated, and the ways that they interact with and are influenced by their social worlds have been explored in research in the natural sciences and the social sciences. Over the past three decades, a shift has taken place in the social sciences, as new understandings about the roles children play in the social realm have emerged, and children are becoming recognized as active citizens with rights, responsibilities, ideas and experiences. While this shift in understanding regarding how children and childhood are perceived has been by no means universal, this shift is occurring on a global scale, both legally in international documents such as the United Nations Convention on the Rights of the Child (UN General Assembly, 1989), and theoretically in scholarly conceptual and philosophical frameworks.

The Convention on the Rights of the Child (CRC) is the first legal document that recognizes children as rights-holding citizens within their societies and the world community (Wells, 2009). It puts forward the notion that children have competencies that are different but just as valid as adults; that these capabilities should be taken into consideration; and that children have a right to be active participants and contributors in their communities. From this point of view, children may be smaller in stature and have less experience than adults, but they are capable of forming their own opinions, and are entitled to be involved in matters that both directly and indirectly affect them. However, it is still uncommon for children to be considered as competent individuals. Their voices are rarely listened to in the public domain, and often discredited as immature or unreliable. Since children are dependent in many ways on the adults in their lives, they are often thought of as vulnerable. This dependency creates an ongoing power 
differential that undermines children's agency and their image as capable beings. Although many nation-states have ratified the CRC and claim to consider children's rights an important issue, children are rarely involved in policy writing, in the development of practices, or in decisionmaking processes in issues that have direct impact on their lives and well-being. If we recognize that research can have a direct influence on policy, practice and decision-making in many aspects of society, one way children's perspectives can have an effect on the mechanisms of governance that affect them is for their ideas and voices to be involved in research. As well, if perceptions of children as uniformly incompetent are to be challenged, children must be given opportunities to demonstrate otherwise. Research has the potential to be a site that offers these kinds of opportunities, but to do so requires that researchers design projects that consider the issues of children and childhood and that involve children as well. This is already happening in contemporary research, and leads to the question at the core of this study: How do researchers involve children in their social research? Although the new social studies of childhood (James, Jenks \& Prout, 1998) is a growing interdisciplinary field, including scholars from anthropology, education, geography, sociology, social work, public health, psychology and child-focused disciplines such as childhood studies and child and youth care, the literature is sparse regarding how research in the field is conducted. In Canada, a nation that ratified the CRC in 1991, and is thus legally committed by international agreement to prioritize the issues of children and childhood, there are no scholarly studies or articles addressing how Canadian researchers involve children in their research. This study aims to make preliminary steps to begin to reduce this gap, by describing how Canadian researchers choose to involve children in their work and by accounting for some of the "mechanisms of engagement" (Dockett \& Perry, 2007, p. 56) used by Canadian researchers to involve children. 


\section{Conceptual Framework}

At the heart of ethical research practice, researchers must work to balance their own needs and the needs of the inquiry process with the needs and rights of the children involved. For the purpose of this study, I am using the definition of children from the CRC in Article 1: "For the purposes of the present Convention, a child means every human being under the age of eighteen years unless under the law applicable to the child, majority is attained earlier." (UN General Assembly, 1989, p. 2) Therefore, unless stated otherwise by participants, the word children is used throughout this paper to signify young people up to the age of 18 . This research study is informed by Wall's (2010) conceptualization of 'childism', and a rights based-approach to childhood as put forward by the CRC. Wall's (2010) notion of childism is parallel to feminism, in that it is an ethical, philosophical, scholarly and practical perspective that accounts for "care, relationality, embodiment and power" (p. 3) in ways that position issues of childhood as central. Wall's questions regarding what is to be learned from childhood experiences, and what purposes and obligations humans have to each other, have been reframed for this study in the following ways: 1) How are children being involved in research?; 2) Why are they being involved in research?; and 3) What are the responsibilities and obligations that researchers have to children who are involved in research? These questions help to shape the discussion of what ethical practices might be when children are involved in research. Childism, as articulated by Pierce and Allen (1975), recognizes the ways in which children have been and are being systemically discriminated against due to their age, and popular conceptions of childhood. Within a framework of childism, the experiences and concerns of children are prioritized. This theoretical perspective will lend a critical lens to this research study, investigating potential explanations for how children are positioned in research. 
A children's rights perspective is the second lens informing this study. From within this perspective, children are viewed as citizens of their communities and of the world who have rights and responsibilities that are different from but as valid as those of adult citizens. This perspective emerges from the CRC (UNICEF, 2006) and from "General Comment 7" (Office of the High Commissioner for Human Rights, 2005), a document that describes in detail different ways that the CRC can be implemented with children in practice, as well as commentary and debate from scholars around the world. In alignment with the rights-based interrogation of research taken by Einarsdóttir (2007), Conroy and Harcourt (2009), Pascal and Bertram (2009), Broström (2012), and Sargeant and Harcourt (2012), the theoretical approach to childhood taken in this study understands that at the foundation of children's involvement in every aspect of private and public life, the three principles that guide the $\mathrm{CRC}$ need to be taken into consideration. These principles are articulated as provision, protection and participation (Zeldin, 2013). Provision refers to the entitlements children have to be afforded the basic necessities that guarantee them health, well-being and access to resources that assist them in attaining their fullest potential. The principle of protection refers to children's rights to be kept safe from harm and exploitation. The participation principle rights entitle children to be recognized as full citizens of their societies, deserving of having their voices heard and being included in decisionmaking processes in matters that affect them. A key element to a rights-based approach is that these three principles are maintained in equal balance with each other, and that one is not privileged over the others. Both childism and a rights-based approach to childhood will provide a theoretical backdrop for this study's exploration of how children are involved in contemporary Canadian research. 


\section{Chapter 2: Review of the Literature}

\section{Introduction}

This literature review explores the body of written work on the topic of social sciences research involving children. The first section examines the literature regarding how children are engaged in research, the range of roles they take and the differences between research conducted on, about or with children. The second section examines literature on the topic of how researchers conceptualize children and the effects of these conceptualizations on research. The final section reviews literature regarding methods used by researchers to engage children in research and literature that takes up researchers' own perspectives regarding their inquiry involving children.

While there is a growing body of work that relates to children involved in research, and how they participate and the researchers' reflections about the process of involving children, there are few primary studies that theorize about the experiences of children and childhood, or explore the ways theoretical ideas influence how children are involved in research. This review includes contemporary studies and theoretical research regarding children's involvement in research as well as texts written in the 1990s when an explosion of theory regarding children and childhood emerged and a number of scholarly journals on the topic of childhood and children (e.g. Childhood and Children \& Society) were established.

A study's topic, purpose and research questions are key elements that determine the ways in which children are involved in the research. Traditionally, researchers have been responsible for deciding what the mechanisms of engagement used to involve children in research will be (Dockett \& Perry, 2007). The different ways that children are involved can be conceptualized as being on a spectrum. At one end of this spectrum, children are the topic of the research - 
involved as objects under observation, the subjects in an experimental process, or generators of the data for a statistical inquiry. At the other end of the spectrum is research that involves children directly in the process of inquiry, either as participants or informants by engaging them in a wide range of data collection methods, or in some cases as co-researchers influencing the research design. The role that children take in research is related to the orientation of the research - whether it is being conducted on children or being conducted with children. At present, there exists a debate in the literature supporting both of these two orientations. The following section explores the body of literature pertaining to how children's roles and the orientation of research influence research design.

\section{The Roles of Children in Research}

Several researchers have written about how children's involvement in research has been defined, but there is no consensus on a definition or on which terms should be used. Researchers variously use the terms 'participation' (Powell \& Smith, 2009; Thompson, 2007), 'involvement' (Pascal \& Bertram, 2009; Uprichard, 2010), 'consultation' (Hill, 2006), 'collaboration'(Conroy \& Harcourt, 2009) and 'engagement'(Dockett \& Perry, 2007; Dockett, Einarsdóttir \& Perry, 2009) to describe how children become a part of research - sometimes interchangeably, and sometimes with clearly differentiated definitions. Whiting (2009) offers a system of differentiation that varies by degree of engagement, which from lowest to highest are: consultation, as an instance of children's views being sought out but not necessarily incorporated into the research design; involvement, when children's perspectives are sought out and children take part in some decision-making in the research process; and participation, where children actively play a part in constructing and carrying out many or all elements of the research design 
and processes. For the purpose of this study, the term involvement is used as it was perceived to most neutrally describe the roles children may take across the spectrum discussed above.

Moules and O’Brien (2012) contrast and critique several models of conceptualizing children's involvement, beginning with Hart's (1992) widely referred-to 'ladder of participation'. Hart's model outlines eight levels of participation of increasing complexity, but has also been criticized by some researchers for its linear and hierarchical system of ranking, which implies that some forms of participation are superior to others, or that one level leads to the next. The authors also examine Chawla's (2001) proposal of a model of seven forms of participation, in contrast with the levels of Hart's ladder. Chawla (2001) contends that the forms in her model acknowledge that appropriate ways to participate will vary depending on the study, participants and context. Children move from one form to the next as their competence increases, and unlike Hart's ladder, Chawla's model allows for forms of participation to overlap. However, this model is also cumulative and children's progression is dependent on their competence with preceding forms, and is similarly criticized by scholars who resist notions of competence being dependent on development. The authors contrast a final model, offered by Treseder (1997). In this circular model, five degrees of participation are presented as spokes of a wheel, with all of them equally valid and valuable. In this model, participation is completely contingent on the type of study and context, providing a flexible array of possible ways to involve children. Given this diversity of terms, definitions and models, it does not seem possible or practical to settle on a single way of defining children's involvement in research. Rather, what emerges is a sense that researchers must consider the purpose and topic of study, and based on these considerations determine which role and orientation to take in their design. 
In discussing the roles children may take in research, Woodhead and Faulkner (2008) contend that much of the traditional scientific research relating to issues of children and childhood positions children as the object or subject of inquiry. The foundational studies of childhood conducted by Skinner (1938) regarding a behaviourist approach to children's development; the work conducted by Piaget (1964) in children's cognitive development; and the studies in attachment theory undertaken by Bowlby (1969) are all examples of research conducted on or about children, which developed out of the natural sciences (Kail \& Zolner, 2009). In a similar vein are research studies inquiring into specific cognitive skills and abilities of children such as research conducted by Case (1991), who worked to identify the stages of children's sense of self, or Barnett et al. (2008), whose study assessed the executive functions of children within a particular early childhood program. Research that engages children as objects of study interprets issues of childhood from a perspective that emphasizes the point of view of the researchers. Large-scale sociological research positioned children largely as objects or subjects (Qvortrup, 1997). Christensen and James (2008) criticize the role of children as objects/subject in research, stating that it does not allow researchers to learn from children's perspectives. They suggest that privileging quantitative evidence can sometimes make invisible the dominant perspectives biased towards measurable data over more descriptive data that is contingent on context or locale. It is important to note that research in which children are objects or subjects offers a different type of insight. While it is true that large-scale quantitative research does not engage with the details of children's experiences, it does offer important insights that allow researchers to trace trends and commonalities across large populations or changes over time, which can be used to direct further research or establish an overview of elements that influence childhood. 
According to the literature regarding children in the role of participants, a different approach to involving children is taken. Children's experiences and perspectives are explicitly sought out as important data. Pascal and Bertram (2009) state that the United Nations Convention on the Rights of the Child (1989) and anthropological and sociological understandings of children's capacities as social agents were both influential developments that contributed to a theoretical shift towards involving children in research as participants. The authors maintain that children have a right to have their voices heard in research that pertains to them, and involving children as unengaged objects of research reinforces the subservient social position children have as a marginalized group. As a way to counter this dynamic, some researchers involve children as part of the research team, who influence the design of the study or may participate in implementing it in the field. As an example, Lundy, McEvoy and Byrne (2011) organized Child Research Advisory Groups (CRAGs), in which child members informed every stage of the research. Researchers who involve children as participants design their research within an orientation of conducting research with children, towards the goal of establishing an insider perspective on children's experience (Tangen, 2008), or by positioning children as experts of issues related to childhood (Broström, 2012; Christensen, 2004). This approach to research centrally values children's voices and perspectives.

While Einarsdóttir (2007) agrees with the stance of involving children as participants, she questions the push to do so without thoughtful consideration. She cautions researchers to be clear about who will benefit from the study, and how this influences children's involvement. She recognizes that the push to involve children as participants in research is often an acknowledgement of their participation rights, but questions whether the push to include children's voices has the potential to compromise children's other rights, such as their right to 
privacy or their right to leisure and play. In the light of this question, it seems crucial that researchers be thoughtful about how they design their research, and be clear about its purpose. One notes that viewed from a rights-based perspective, researchers must consider and balance the entire range of children's rights - protection, provision and participation, in order to acknowledge the full breadth of children's rights. This is not an easy task, and requires researchers to thoughtfully consider how this balance can be achieved in each aspect of the research design, and within the context of each new study.

The literature suggests that depending on the research design and the topic of study there is a range of possible ways children can be involved in research. Abbot and Langston (2005) offer the idea of fitness for purpose as a criterion for choosing how to design research involving children and which mechanisms of engagement are most appropriate. This notion of fitness for purpose returns us to the idea of a spectrum of children's roles in research and suggests that rather than considering children as objects of or participants in research being oppositional positions, they are rather options within a continuum of equally valid and valued choices. What choices researchers make regarding the roles of children and the orientation of a particular research study are largely informed by the ways that researchers perceive children. Children can be viewed in a variety of ways - as capable and as incapable, as developmentally limited and as agentic social beings - in different variations, degrees and contexts. These conceptualization of children have a direct influence on research design, as explored in the following.

\section{Conceptualizations of Children and their Influence on Research}

The following section of the literature review discusses the body of scholarly work pertaining to how researchers conceptualize children and childhood, and how different ways of seeing affect research design. The body of literature suggests that children are understood by 
researchers in two overarching ways, referred to here as the developing child and the social child. These two ways of framing children and childhood emphasize a different aspect of human experience as the fundamental force that shapes children.

The developing child is conceptualized within a biological and maturational perspective that describes human growth and the acquisition of skills and knowledge as being a process of cumulative stages based on chronological development. This way of seeing children is based on traditional scientific views of childhood as a primarily biological phase of human development that find their foundation in the natural sciences (Freeman \& Mathison, 2009). Woodhead (2005) describes this view of development as defined by three Ns - natural, by which he means that childhood is linked to biological processes of maturation and growth; normal refers to children developing along universal patterns based on measured averages; and the third n, needs, emphasize the requirements for ensuring that children's natural development proceeds along normal lines. For almost a century, this conceptualization of children has been at the heart of the field of developmental psychology, the oldest form of child study in the social sciences (Kail \& Zolner, 2009). According to Hogan (2005), the notion of the developing child is taken up in the field of developmental psychology to understand how the psychological functioning of children changes over time. She states that the majority of such research is conducted to document agerelated competencies and to determine how children's acquisition of skills and knowledge contribute to "positive functioning in adulthood" (Hogan, 2005, p. 24).

In contrast, the social child is conceptualized as a social construction contingent on culture and other social categories, as well as time and geography. This way of seeing children is based on anthropological and sociological understandings that childhood experiences are subjective and multiple, and largely dependent on the understandings and expectations of a 
particular cultural milieu. Woodhead (2005) outlines this way of understanding children's development and experiences through a social perspective he describes as the three Cs - context, culture and competencies. Context is the idea that notions of childhood are dependent on time and space; culture refers to the ways that different social groups influence our understanding and expectations of and for children; and competencies are children's skills and capacities determined by their individual developmental pathways. This contextual perspective is articulated in social science research as the 'new social studies of childhood' (James, Jenks \& Prout, 1998) or the 'new sociology of childhood' (Matthews, 2007), and focuses on describing childhood experience instead of measuring its constituent elements (Freeman \& Mathison, 2009).

Contrasting these ways of conceptualizing children feels somewhat like furthering the exhaustive debate of nature versus nurture, which given the complexity of the task of isolating biological influences from those elements of culture that shape children seems an insurmountable task. However, the distinction is made here to illustrate a line that appears to be drawn in the body of scholarly work regarding research involving children. It seems evident that both of these ways of seeing children have implications for research design and the ways children are involved, as they influence whether researchers view such research as the same as or different from studies conducted with adults. Grieg, Taylor and MacKay (2007) acknowledge that children are not the same as adults and explain that these differences require that research be designed differently. These authors maintain that children hold a special position in society, which they describe as being potentially rooted in the ways that they differ from adults, the fact that our species is dependent on their existence for its survival, or because adults understand so little about them. From these authors' perspective it "is evident that children have, from biblical 
times to the present day, been singled out to varying extents as being exceptional beings who have been afforded special consideration" (p. 5) and it is therefore incumbent on researchers to conduct research involving children in ways that recognize their specialness. While the underlying meaning of respect these authors intend to convey is laudable, the idea that children are "special" has the potential to reinforce ideas that children's differences are so significant that they are another order of creature entirely from adults. According to Nutbrown (2011), this process is an "Othering" (p. 7) of children, in which they become an exotic specimen or the members of an alien tribe based on their "special" status. Doing this has the potential to occlude children's actual experiences in a way that is patronizing, unscientific and ultimately disrespectful to them, as it interferes with researchers' abilities to perceive them as human beings. Viewing children from this perspective also has enormous potential to bias the analysis and interpretation of research, making any data children provide as special. It is possible to draw parallels between this idea and the discourse of special needs in early childhood education and care. Disabilities studies discourses and research designed to intentionally involve children with disabilities such as the work of Phelan and Kinsella (2013) work to actively dismantle notions of children as special, and acknowledge that while children may be different, their value is not located in their differences.

In contrast, Punch (2002) examines the question of research involving children as being different from or similar to research that involves adults. She does so by first examining the ways that researchers' perceptions of children affect how they listen to them in research. When children are perceived as being the same as adults, Punch contends, then the research designs and methods used to collect data are the same. However, she cautions that conducting research involving children in exactly the same way one would with adults may not account for the power 
imbalances that already exist between adults and children, and which have the potential of affecting the research. On the other hand, Punch relates that when research is conducted from the point of view that children are different from adults, there is a risk as well. An ethnographic approach to the different worlds of children requires that as adults, researchers must contend with the fact that they are not full participants in those worlds and therefore are not fully equipped to interpret the issues under study. Punch notes further that adults' analyses of children's experiences may also be influenced by their personal remembered experiences and meanings, thus muddying their interpretation. Avoiding this involves high levels of reflection and requires researchers to be able to clearly bracket their own standpoint, which can be a challenging undertaking. In her work with school children in Bolivia, Punch uses what she refers to as 'task-based' methods of data collection. Using drawings, photography, written diaries, worksheets and Participatory Rural Appraisal (PRA) techniques, such as activity tables or matching diagrams, the aim of her study was to gain deeper understanding of how children in rural areas of the country negotiate their emerging independence. By reflecting on this work, Punch examines in depth the benefits and challenges of each method, as well as the advantages entailed in combining more than one method. Punch concludes that trying to identify adult research methods or child research methods is a misleading debate, as methods in well-designed research are contingent on the context of the research as much as the participants' characteristics. She argues that it is too simplistic to consider research with children as either the same or different as research involving adults. Given that the complexity and number of factors involving context and the characteristics of participants need to be considered, Punch suggests a continuum of research that moves between notions of same and different. Research involving children should move along this continuum according to the constituent factors of the study at hand. It is 
important to note how this flexible and reflexive approach to research design resolves the sameor-different debate by emphasizing the need to fit the study's methods and philosophical approach to children with the topic of study in a pragmatic way, and demands that researchers be reflexive about their research designs with each new study, similar to the suggestions made by Abbot and Langston (2005).

Uprichard (2008) suggests a similar stance that also has potential to resolve what she refers to as "the antagonism" (p. 303) between the two perspectives discussed by Punch (2002). By incorporating the idea of temporality, that children are subjects of the passage of time, Uprichard maintains that children can be seen as simultaneously becomings who develop chronologically from childhood into adulthood, and beings who are active social actors in the present. According to Uprichard all humans, regardless of age, are 'beings' always engaged in the act of 'becoming'. She draws on Prigogine's (1980) ideas of temporality, which describes time as the concepts of 'being' and 'becoming' in interaction, outlining a strong connection between time and change. If researchers intentionally incorporate the passage of time into their conceptualizations of children, they can be seen as developing competence in some areas while having attained competence in others. Uprichard notes that competence is not a complete or universal characteristic children or adults, who can be competent and incompetent at different tasks or in different capacities, even in regard to the same skill. With the passage of time, a child (or an adult) can on one day demonstrate competency in a skill and the next day not be able to achieve the same level of competency. This idea of seeing children through stereoscopic lenses of being and becoming simultaneously offers a perspective on children and childhood of much greater richness and depth, and can contribute to researchers designing research that acknowledges their experiences from both perspectives. Methods used in both approaches can be 
combined, such as in mixed methods research, to account for a wider range of children's experiences.

This suggests that by applying the idea of a continuum to same-different or beingbecoming as suggested by Uprichard and Punch, we can reposition what appear to be "antagonistic" beliefs regarding children and childhood within a wider field, as possible options. These options can be considered to have equal value, and when researchers intentionally consider how their beliefs about children influence their research design, they are able to design research that is more aligned with their values and may involve children from a more thoughtful position. With these ideas in mind, the next section of the review examines what mechanisms researchers use to involve children in research, and how reflection may be a useful technique in designing such research.

\section{Researchers Involving Children in Research}

Dockett and Perry (2007) describe methods of data collection as the primary mechanism of engagement for children in research, whether they are respondents, participants, or involved in conducting the data collection themselves. A scan of the literature shows that there has yet to be a systematic review that catalogues methods used in research involving children. This section of the review therefore relies on a range of texts that address the topic of conducting research involving children.

Goodwin and Goodwin (1996) discuss how different methods of data collection are used in quantitative and qualitative research. These authors distinguish between quantitative measures used in experimental and quasi-experimental designs, such as standardized cognitive, affective and psychomotor measures; questionnaire and observation schedules; and structured interviews (including individual interview and focus groups); and qualitative methods such as participant 
observation techniques; semi-structured and open-ended interviews (which also can be conducted individually or in groups); and the creation and collection of documents (diaries, letters, etc.). According to Goodwin and Goodwin, all of these methods are valuable and valid for research involving children. Both Greene and Hogan (2005) and Mac Naughton, Rolfe and Siraj-Blatchford (2010), concur with Goodwin and Goodwin, dedicating entire chapters to surveys and questionnaire, interview techniques, observational methods, ethnographic tools and document collection in their books.

Continuing the discussion of methods used when involving children in research, Dockett, Perry and Einarsdóttir have engaged in a collaborative discussion across multiple articles on the topics of children's participation and children's trustworthiness as informants in research (cf. Dockett \& Perry, 2007; Dockett, Einarsdóttir \& Perry, 2009; Dockett, Einarsdóttir \& Perry, 2012). These authors discuss a number of their studies in which children are considered participants, and how their work highlights a commitment to listening to and hearing the voices of children as participants in research by using different methods to include children's perspectives. Their intentional use of multiple methods with children is an explicit acknowledgement of children's right to express themselves in ways that they feel most comfortable, which may involve a diversity of methods. Clark and Moss (2001) developed the Mosaic approach to directly address this issue. The Mosaic approach combines visual methods of data collection such as mapping and drawings that children regardless of proficiency in or ability with language can engage in with narrative data collection techniques. Clark and Moss contend that this combination of multiple methods allows children to express themselves in a variety of ways, and allows researchers to piece together a thicker description of the topic under study. 
Few primary studies have been conducted on the topic of methods used in research that involves children. Hill, Laybourn and Borland (1996) discuss how the theoretical shift in the 1980s and 1990s towards viewing children as active and capable social agents rather than simply passive recipients of the socialization imposed on them by adults also has methodological implications for research design. The authors note that while psychology, up until that point the social science discipline most involved in the study of children, had developed a wide range of techniques that facilitated children's communication in research, there was also a tendency in this field to use methods which were standardized and produced quantifiable results, and that qualitative approaches were mainly used in the pilot stages of research. These standardized methods included surveys and questionnaires, observation of children's behaviours, psychological assessments and interviews. Baker, Panter-Brick and Todd (1996) also investigated the types of methods used in research with children, contextualized within a mixed methods anthropological comparative study of the quality of life of homeless street children in Nepal. Quantitative research methods including anthropometric surveys, physical measures such as saliva collection and heart rate monitoring, structured observation, and a demographic survey were combined with more qualitative methods such participatory appraisal exercises, a peer personality assessment using photography, popular education programmes, and semi-structured and informal interviews to investigate the life-experiences of Nepali street children. Children were also involved in participatory research processes such as focus groups, filming a video and working with a youth researcher to conduct informal interviews with peers. The authors reflect on this combination of methods, and how it provided a thick description of many elements of children's quality of life in Nepal. 
Other researchers have developed numerous techniques that combine different modes of knowledge production (such as visual media and written texts), and employ arts-based methods such as painting, collage, or model-making. Punch's (2002) task-based methods as previously described in this paper are one example. As another, Kirova and Emme (2007) discuss the use of data collection techniques that incorporate visuality, movement, play and narrative methods contextualized in their research involving immigrant children. They use fotonovelas, which combine photographs and storytelling into multimedia narratives, as a way to both elicit and document data simultaneously, and interviews involving board games as a play-based approach to data collection and power-sharing in a research context. These methods are excellent examples of innovative, multi-modal data collection practices used in contemporary research involving children. With such a large assortment of methods to use in data collection, it is not surprising that a systematic review of methods used in research that involves children has yet to be conducted. However, given this wide variety of mechanisms of engagement, a question arises as to what researchers think about their experiences using them in research involving children.

Spyrou (2011) addresses this question in a discussion regarding the necessity for researchers to reflect on how power and ideology interact and influence the processes of research and children's involvement with those processes. He states that because of the social position of children and the power dynamics inherent in adult-child relationships, adult researchers have an enhanced ability to "re-present" (p. 160) the data generated by research involving children in ways that are different than research with adults. He further states that it is an ethical issue for researchers to acknowledge and work with these dynamics in especially reflexive and transparent ways. He suggests that researchers consider each element of the research process - conceptual 
framework, design, methods chosen for data collection and the procedures of analysis - through lenses sensitized to issues of power, participation and representation.

Similarly, Phelan and Kinsella (2013) view reflexivity as a tool with which to continuously sensitize researchers to the processes of research, and to make research more accountable to and ethical for all parties involved. Grounded within their experiences of involving children in research, in particular children with disabilities, they discuss the challenges and benefits of "enacting reflexivity in our everyday research practice." (p. 87). According to the authors, reflexivity is an indispensable element of research design that must be used deliberately and continuously throughout the research process to ensure that it is ethical for all involved. For the purpose of their discussion, they draw on an ethical distinction made by Guillemin and Gillam (2004) to define the scope of ethical research. Guillemin and Gillam (2004) distinguish ethics as falling into two categories: procedural ethics, which involve the policies and procedures that must be met in order to gain approval from research ethics boards and review committees; and ethics in practice, which are the everyday ethical issues that must be negotiated within research practice. Phelan and Kinsella recommend reflective practice as a primary means of making research involving children ethical. To do so, the authors contend that reflexivity can be used to in the following ways in research involving children: to attune researchers to their participants; to assist in negotiating potential risks and pitfalls by preparing researchers through forethought; to make researchers more aware of their preconceived assumptions regarding children and childhood by considering how these might influence research design and interactions with children; to pre-emptively and responsively develop strategies and methods in research to contend with power dynamics; and to determine effective and respectful methods of representing children in interpretation and dissemination. However, the authors acknowledge that 
reflexivity is not a simple panacea, and that continuous critical reflection can be a daunting and challenging task. Therefore, they outline several frameworks developed by other scholars to support researchers in reflective practice, such as Nutbrown (2010), who interrogates ethical issues of the representation of young children when using arts-based methods, and Warin (2011), who expands on the link between reflection and "ethical mindfulness" (p. 806). As another means of supporting researchers in adopting reflection as a part of their ethical research practice, Phelan and Kinsella offer a collection of questions to be used to guide reflexive research with children. It is evident that both Spyrou (2011) and Phelan and Kinsella (2013) value how reflective practice in research can furnish researchers with additional information and insight that can influence the design of more thoughtful, responsive and appropriate studies. By questioning the choices they make in their own practice, critically reflecting on the outcomes of those choices, and applying lessons gained from reflecting on their practice, researchers can become better research practitioners.

To further explore how researchers involve children in research, a search of the literature revealed two studies that investigate researchers' choices when designing research involving children, both of which occurred in New Zealand. Dalli and Te One (2012) conducted an investigation into the experiences of researchers who involve children in their research. The authors interviewed eight researchers about the methodological challenges they faced and the creative efforts they undertook to be as authentic as possible in collecting, analyzing and interpreting data about children's experiences. The authors grounded this inquiry in the assumption that most contemporary childhood researchers are influenced by two things - an awareness of children's rights and the pedagogy of listening. The authors state that first, most researchers conduct their research in accordance with Articles 12 and 13 of the CRC (1989), 
which describe children's entitlements regarding their rights to forming, expressing, and having their opinions taken seriously. The second of these influences, the pedagogy of listening proposed by Rinaldi (2006), urges adults to attend to the multiple ways children express themselves. While these two elements are present in some of the body of knowledge on the topic, and some of the literature taken up in this review, it is perhaps an overstatement that the CRC and the pedagogy of listening have influenced "most contemporary childhood researchers" (Dalli $\&$ Te One, 2012, p. 225). However, despite this generalization, the authors present insight into some common experiences among their participants. In interviews, Dalli and Te One asked researchers to reflect on their experiences, an activity that revealed that researchers are concerned with several issues that are also predominant in the literature. These common issues are: understanding children as reliable informants, and creating time and space that assist children in being heard; the 'messiness' of research with children, and how it may be best to expect the unexpected; the particular investment of time and resources necessary when building relationships with children, their families and the professionals working with them to create ethical research contexts; and practices that negotiate the tension that can exist between children and culture, while at the same time being respectful of each (Dalli \& Te One, 2012). Participants provided insightful examples that illuminated each of these issues with details and reflections on their own work. The authors conclude with a discussion of the notion of fitness for purpose, as discussed by Abbot and Langston (2005), in which there are no universal best practices for conducting research with children, and that a wide array of methodologies and methods must be considered to find the best fit for each particular inquiry.

Powell and Smith (2009) conducted a similar study, asking researchers in the social sciences to reflect on how they encouraged the children participating in their research projects to 
explore their participation rights, and the outcomes of such participation. Via an email interview process, the authors were able to involve 12 researchers from a range of disciplines including childhood studies, health, law, social work, geography, psychology and education in a process of reflecting on their experiences of children participating in their research. These participants reported on issues and challenges faced when involving children in their research. Issues discussed included ensuring that research methods were appropriate to their samples' capabilities; perceived vulnerabilities of children when inquiring into topics of a sensitive nature; contending with the intricacies involved in securing ethics approval when working with a population viewed as vulnerable; finding ways to balance power between the adults and children involved; equitable consideration of cultural values and the interests of children; and the influence adults and the research environment have on both recruitment and informed consent/assent processes. While most of the participants felt that children benefit from research, the authors note that a "protectionist discourse" (Powell \& Smith, 2009, p. 138) prevalent in interactions with children position them as vulnerable and heighten the need for adult protection. Powell and Smith critique this perspective by maintaining that it is social and political assumptions regarding children's abilities and competencies that create and reinforce an environment in which children are thought of as vulnerable and in constant danger, not children's biological immaturity. Most participants felt that children's rights were best upheld and that children were most protected by participating in research, arguing that having intentional spaces that valued accounts of children's experiences in their own voices worked to counter misinformed assumptions about their capacities, and also had the potential to affect change in children's contexts. Powell and Smith note that choices made by researchers regarding ethical and methodological issues have an impact on how children participate, and urge 
researchers to hone their communications skills, take time to establish relationships, and design their research guided by a child-centric perspective. One can note that by participating in this reflective process, participants of Powell and Smith's study benefitted from articulating their experiences and gained clearer insight into their own research that involved children. This is can be understood as another endorsement for reflective practice in research involving children.

This literature review outlines the development of research involving children, and the array of choices presented to researchers when designing such research. However, the gap in the literature regarding how researchers in Canada involve children in research remains, and is the impetus for this research paper. With the aim of describing the topography of current Canadian research involving children, this research study seeks to address the following questions: "What research designs are contemporary Canadian researchers choosing to use when involving children in research?" and "What are some of the elements that Canadian researchers must take into consideration when conducting such research?" 


\section{Chapter 3: Methods}

\section{Methodological Approach and Rationale}

In this study, a mixed method approach was employed to identify research designs used by Canadian researchers who involve children in their inquiry. The rationale for a mixed method approach for this study was to collect data in a variety of ways in order to provide a rich description of such research (Creswell, 2009). Combining data collection and analysis methods from both quantitative and qualitative approaches was felt to reflect the complexity of the research landscape, as well as the diversity of approaches actually employed in research involving children. Using multiple methods also has the potential to provide a more complete picture through a process similar to triangulation (Denzin, 2012; Flick, 2007). In fact, a crystal is a more accurate model for qualitative research than a triangle, in that it captures ideas of dimension and the existence of multiple facets of experience (Dockett \& Perry, 2007; Ellingson, 2009; Richardson, 1994). In this study, multiple methods were used to acknowledge and account for the dimensional and textured nature of lived experience, described by Ellingson (2009) as crystalline.

Qualitative inquiry acknowledges that lived experience is complex and investigates the meanings attributed to a particular event or phenomenon by the parties involved (Creswell, 2009). Given that the aim of this study was to examine how Canadian researchers design and implement research involving children, a qualitative descriptive approach was the primary methodology taken. In their discussion regarding the value of qualitative descriptive research to novice researchers, Magilvy and Thomas (2009) explain that the use of such a methodology has the potential to contribute to understanding participants' experiences within a particular context, as it provides a rich description of those experiences. Sandelowski $(2000 ; 2010)$ argues that a 
qualitative descriptive study is an ideal method to use when a rigorous account of an event or phenomenon is desired, rather than when the goal of a study is to develop theory or identify the essence of phenomena. She refutes the popular notion that qualitative descriptive study does not have the analytical rigor to be considered a viable methodology in its own right. Her argument challenges the notion popularly held by quantitative perspectives that descriptive inquiry is "nonexperimental and weak" (p. 334), and merely an accounting of the details of the event without analysis. Sandelowski's claim is that the "data-near" $(2010$, p. 78$)$ findings produced by a qualitative descriptive study are nuanced in detail and their meanings interpreted as a "reading of lines as opposed to into, between, over, or beyond lines" (italics in the original, 2010, p. 78). An interpretation that retains such fidelity to the data collected from participants is ideal for this research project, which has as its aim to give an account of the landscape of contemporary Canadian social research involving children. A qualitative approach to how research is conducted when it involves children that focuses on the meanings that researchers hold about why and how they conduct such research, could significantly contribute to our understanding of research involving children (Creswell, 2009). According to Denzin (2012), research has the potential to "interrogate the ways in which power, ethics and social justice intersect", based on his belief that qualitative research scholars have an obligation "to engage in ethical work that makes a positive difference" (p. 86). By listening to the voices of researchers, this study aims to illustrate participants' experiences to better understand the ethical considerations necessary in research that involve children. For these reasons, a qualitative descriptive study in which foundational data supplied via a questionnaire is contextualized by qualitative interviews, is an ideal methodological approach to use in the present study. 


\section{Participants and Recruitment}

Purposeful sampling was used to recruit Canadian researchers who involve children in their research. Creswell (2009) justifies purposeful sampling as an ideal method to identify participants who can help the researcher understand the issue under investigation. Englander (2012) states that in phenomenological research when considering the sample of their study, researchers must ask the question: Does this person have the experience that I am looking for? In order to get a broad understanding of the multiple experiences of conducting research involving children, cross-sectional sampling allows for the collection of data on a specific topic from a wide variety of participants to describe patterns of relation between variables or common themes (Frankfort-Nachmias \& Nachmias, 2008). In this study, researchers conducting research from various disciplines and in several academic departments at post-secondary institutions across the country were recruited to provide as comprehensive a description of their research design choices and experiences as possible.

Recruitment criteria consisted of researchers who were currently conducting or had recently conducted research involving children; were working within a Canadian institution; and were within a social science discipline inquiring into issues relating to children and childhood. Given the limitations of time and scope of this study, the entire range of disciplines involving children would have been impossible to canvas for potential participants. Therefore, the following social science disciplines were targeted: anthropology, child and youth care, early childhood education, early childhood studies, education, nursing, psychology, public health, social work and sociology.

As a graduate student in a faculty of Early Childhood Studies where researchers are engaged in conducting research involving children, the researcher first contacted this faculty to 
recruit potential participants as a sample of convenience. Next, the researcher's academic advisor was asked to suggest potential eligible participants from within her network of professional contacts. After these potential participants were contacted, the researcher then conducted a search for potential participants among researchers at Canadian universities within targeted departments. Universities were identified via an online search, and relevant researcher and faculty profiles were reviewed to identify participant candidates.

Once potential participants were identified, they were sent a request to participate email detailing the research purpose and procedures, accompanied by an attached information letter and consent agreement. The email outlined the intent of the study and the three-stage process of data collection (questionnaire, interview, and member checking process). A total of 267 Canadian researchers were contacted. Of these, 51 researchers responded, with 35 agreeing to participate and 16 declining. Consent to participate was obtained from 30 out of 35 participants who agreed to participate. The remaining five participants did not complete the consent process and were removed from the pool of participants.

Consent to participate was obtained via telephone or face-to-face conversation, allowing participants to ask questions and to ensure informed consent. In the case of telephone conversations, formal consent statements were recorded over speakerphone, and during face-toface meetings, a consent agreement was signed and archived. Participants were asked whether they were available and interested in participating in the second stage interviews during the consent process, and their availability and interest were noted. To categorize the cross-sectional nature of the departments within which the participants conducted their research, respondents' departments were collapsed together to form seven representative departments: Child and Youth Care, Early Childhood Studies/Education, Education, Health (combining respondents from 
Nursing and Child Health), Psychology, Social Work, and Sociology/Anthropology.

Respondents were located across the country, with at least one respondent from each province. However, a majority of respondents were located in Central and Eastern Canada; six participants were located in British Columbia, and the remaining participants responded from Alberta, Saskatchewan, and Manitoba. No participants were located in the Northwest Territories, Yukon, or Nunavut.

\section{Data Measures and Collection}

The quantitative aspect of this study consisted of the development of an online questionnaire (see Appendix A) that included both closed format leading questions to determine methods used in research, and open format narrative questions to contextualize the research approaches taken by the respondents. Creswell (2009) describes surveys or questionnaires as a data collection tool that offers an easy and structured method to collect and quantify data. Trends within a studied sample can be identified when participants respond to surveys or questionnaires, and in quantitative research these trends may be generalized to a larger population. In this study, the questionnaire was employed to collect descriptive statistics regarding research involving children in Canada, most notably to identify data collection methods most and least popularly

used. Researchers were asked to indicate whether they had used, planned to use, or had not used particular data collection methods to provide insight into what research designs were and are currently being used and how children were involved. The questionnaire was completed by 30 respondents.

Semi-structured interviews were used to gather narrative data relating to current and past research projects, philosophical orientation, challenges and barriers faced by researchers involving children in research and key experiences and insights emerging out of such research. 
These interviews contextualized data collected from the questionnaires, and provided more indepth insight into researchers' designs and ways of involving children in research. Creswell (2009) explains that interviews are a useful way for participants to supply background information and simultaneously provide the research with opportunities to probe participant responses to deepen the data provided. Frankfort-Nachmias and Nachmias (2008) describe the semi-structured interview as a focused interview, which involves a structured encounter that maintains enough flexibility to stay on topic but to also allow for other subjects of discussion that emerge out of participant responses to be pursued. An interview guide was developed to give a common structure to the interviews, consisting of open-ended questions on the topic of researchers' experiences of conducting research involving children with the goal of contextualizing their design choices (see Appendix B.) The researcher focused on active listening techniques during the interview process, and in the spirit of the focused interview discussed by Frankfort-Nachmias and Nachmias (2008), ensured that the interviews were flexible enough to make space to explore themes with the participants as they emerged in conversation.

Given that the participants of this study were situated across Canada, telephone or Skype interviews were conducted. Cachia and Millward (2011) note that although face-to-face interviews are the preferred method of interviewing, telephone interviews were found to provide rich data on par with face-to-face interviews, with the added advantage of being able to interview participants separated by distances. The authors base their claim on the longitudinal study they conducted to establish the suitability of telephone interviews in which they conducted three telephone interviews were conducted over a one year period at three, six and 12 months. A qualitative comparison of the rich results drawn from the data indicated that the telephone is a 
viable medium for data collection (Cachia \& Millward, 2011). For the current study, this viability was extended to voice-only Skype communication. In total, seven interviews were conducted with Canadian researchers who involve children in their work to establish a rich description of contemporary research involving children in Canada.

\section{Research Methods for Involving Children - Questionnaire.}

The online questionnaire was developed by the researcher in order to gather both quantitative and narrative data on participants' research designs that involve children. Using Google Forms, an online survey building function available through Ryerson Google Applications, a secure online questionnaire environment was constructed combining closed format leading questions and open format questions. A list of methods was compiled based on a review of the literature, and were organized into categories based on type of method and materials used. The 15 categories included 45 methods in total, ranked alphabetically, and participants were asked to indicate whether they had used, had not used, or planned to use each. Space was provided for commentary and the addition of methods used in research involving children not listed in the questionnaire. Please see Appendix A for the online questionnaire.

Demographic information was collected via a set of closed format leading questions regarding years of experience conducting research involving children, the ages of children involved and the researcher's attained level of education, and was supplemented with a set of open format questions regarding the researchers' motivations for involving children in research, and specific information about their research, such as the languages and settings in which they conducted research. Researchers were also asked to indicate their discipline of study and the department in which they conducted research. This information was used to organize and contextualize respondents' research experiences. 


\section{Interviews.}

Of the seven semi-structured interviews, six were conducted via telephone and one via Skype from the researcher's home office. An interview guide (see Appendix B) was provided to the participants via email at the beginning of the interview to ensure consistency and comprehension. While the guide provided a structure, the interviews maintained a conversational tone that allowed for both the researcher and participant to follow emerging lines of thought with flexibility and responsiveness. After data were analyzed, a member checking process was conducted via email to ensure that the researcher was presenting participants' voices authentically. Six out of seven researchers interviewed responded with feedback and encouragement.

\section{Procedure}

Upon completion of the consent process, a link to the questionnaire was sent out via email to participants. All thirty participants successfully completed the questionnaire. Questionnaires were completed over a six-week period from May to mid-June 2013, at the end of which potential interview participants were selected from the respondents, controlling for geographic dispersal and targeted department. For analysis purposes, and to render data less identifiable, geographic dispersal was accounted for by dividing Canada into three sections West, which included British Columbia, Alberta, Saskatchewan and Manitoba; Central, which included Ontario and Quebec; and East, which included New Brunswick, Nova Scotia, Prince Edward Island, and Newfoundland. As the distribution of respondents and departments was not even, selection was controlled with this in mind. Seven interview participants were selected from the potential pool, one from each department. When possible, potential interviewees were drawn by department from all three geographic zones. However, some departments had only one 
potential participant, and respondents in some departments were only located in certain areas.

Table 1 details the distribution of respondents and interviewees, by zone.

Table 1

Distribution of Participants

\begin{tabular}{llll}
\hline Department of research conducted & $\begin{array}{l}\text { No. of } \\
\text { respondents }\end{array}$ & Location of respondents & Location of interviewees \\
\hline Child and Youth Care & 2 & West, Central & Central \\
Early Childhood Studies/Education & 11 & West, Central, East & East \\
Education & 11 & West, Central, East & Central \\
Health & 2 & Central & Central \\
Psychology & 2 & West, East & West \\
Sociology/Anthropology & 1 & East & East \\
Social Work & 1 & Central & Central \\
\hline
\end{tabular}

Eligible interviewees were contacted via email to see if they were willing and were available to participate in the interview process. Interview sessions were scheduled accordingly and lasted between 28 minutes and 53 minutes.

\section{Data Organization}

Audio consent files, data and identifying information were kept on a computer, with backups stored on a separate USB drive. Raw online survey data were housed on Ryerson University servers, and accessible only through the researcher's password protected account. Once analysis began, data were organized by date of response and department. Audio recordings of interviews were recorded on a digital recorder and then uploaded into Nvivo 10 for data analysis. To ensure confidentiality, paper field notes contained no identifying information, and were transcribed into word documents or directly onto audio files.

\section{Data Analysis}

Quantitative and qualitative data were analyzed separately and the results combined to provide a description of the research involving children being conducted by contemporary social researchers in Canada. Quantitative data analysis was conducted using SPSS to determine frequency distribution, and qualitative data were analyzed via thematic network analysis. 


\section{Analysis of online questionnaire.}

Thirty $(\mathrm{N}=30)$ respondents from ten provinces in Canada completed the online questionnaire. Data from closed format leading questions regarding which data collection methods researchers had used, planned to use, and had not used were assigned numerical value and inputted into SPSS for statistical analysis. The initial 15 categories of data collection methods were combined into nine categories to facilitate analysis. Organizing the methods into these categories made it possible to determine the category of data collection most and least frequently reported as being used by the participants in this study. Table 2 presents a summary of the variety of methods and their reorganization into nine categories.

Descriptive statistics are used to describe the midpoint of scored responses by measuring the central tendency to provide the average score of a particular test or question (Fisher \& Marshall, 2009). The central tendency of participants' responses regarding whether they had, planned to, or had not used each method listed in the questionnaire, was used to determine the frequency of reported use of each method within the sample. Missing variables resulting from participants not responding to particular questions were accounted for. 
Table 2

Data collection categories

\begin{tabular}{|c|c|}
\hline Data collection methods & Category of data collection method \\
\hline $\begin{array}{l}\text { sorting } \\
\text { matching } \\
\text { computer-based text } \\
\text { paper and pencil } \\
\text { worksheets } \\
\text { questionnaires }\end{array}$ & Activities \\
\hline $\begin{array}{l}\text { performance-based } \\
\text { photography-based } \\
\text { picture-based } \\
\text { sculpture-based } \\
\text { visual media-based }\end{array}$ & Arts-based methods \\
\hline $\begin{array}{l}\text { dialogue } \\
\text { interviews (structured, semi-structured, open-ended) } \\
\text { focus groups }(2-3,3-5,6-10,10+\text { children })\end{array}$ & Conversational methods \\
\hline $\begin{array}{l}\text { Pre-test/Post-test } \\
\text { experimental/control group }\end{array}$ & Experimental methods \\
\hline Tours of children's spaces & Kinetic methods \\
\hline $\begin{array}{l}\text { Pedagogical documentation } \\
\text { learning stories } \\
\text { Mosaic approach }\end{array}$ & Multi-modal methods \\
\hline $\begin{array}{l}\text { non-participatory } \\
\text { participatory observation }\end{array}$ & Observational methods \\
\hline $\begin{array}{l}\text { Audio recordings } \\
\text { video recordings }\end{array}$ & Recordings \\
\hline $\begin{array}{l}\text { toys and dolls } \\
\text { puppets } \\
\text { games (movement or board games) }\end{array}$ & Toys and play-based methods \\
\hline
\end{tabular}

\section{Analysis of interviews.}

Audio recordings of interview sessions were uploaded into NVivo 10, and were used as the foundation for multi-media transcriptions. Following the thematic network analysis outlined by Attride-Stirling (2001) the data collected from interviews were reduced and abstracted to 
identify basic, organizing and global themes upon which to focus the analysis and interpretation. Annotations were made directly onto the audio recordings of the interviews, in order to highlight points made in the audio recording. These multi-media transcriptions were then compiled into annotation documents, combining data from the audio files and the written annotations to create data-rich documents summarizing the main ideas offered by the participant during the interview.

As a part of the member-checking process (Carlson, 2010), each interview participant was asked to review their respective annotation document, to verify that their voice and ideas were being presented in authentic ways. Participants were contacted via email, which also contained a final question regarding the benefits of participants reflecting on their research design. Six out of the seven interviewees responded to the member checking process, offering minor suggestions to help clarify their positions. During the member checking process, participants were asked to contribute a pseudonym to be used when referred to directly in the paper.

Once participants had provided feedback and vetted that the annotation document represented their voices and ideas in authentic ways, they were also entered into Nvivo 10 and coded. The initial reduction of the interview data produced 84 nodes, which were used as the basic themes for the network analysis process. These basic themes provided the building blocks with which to assemble nine organizing themes, which upon further analysis were brought together within three broad global themes used to guide the analysis and interpretation. Figure 1 illustrates the global and organizing themes. 
Figure 1: Global and Organizing Themes

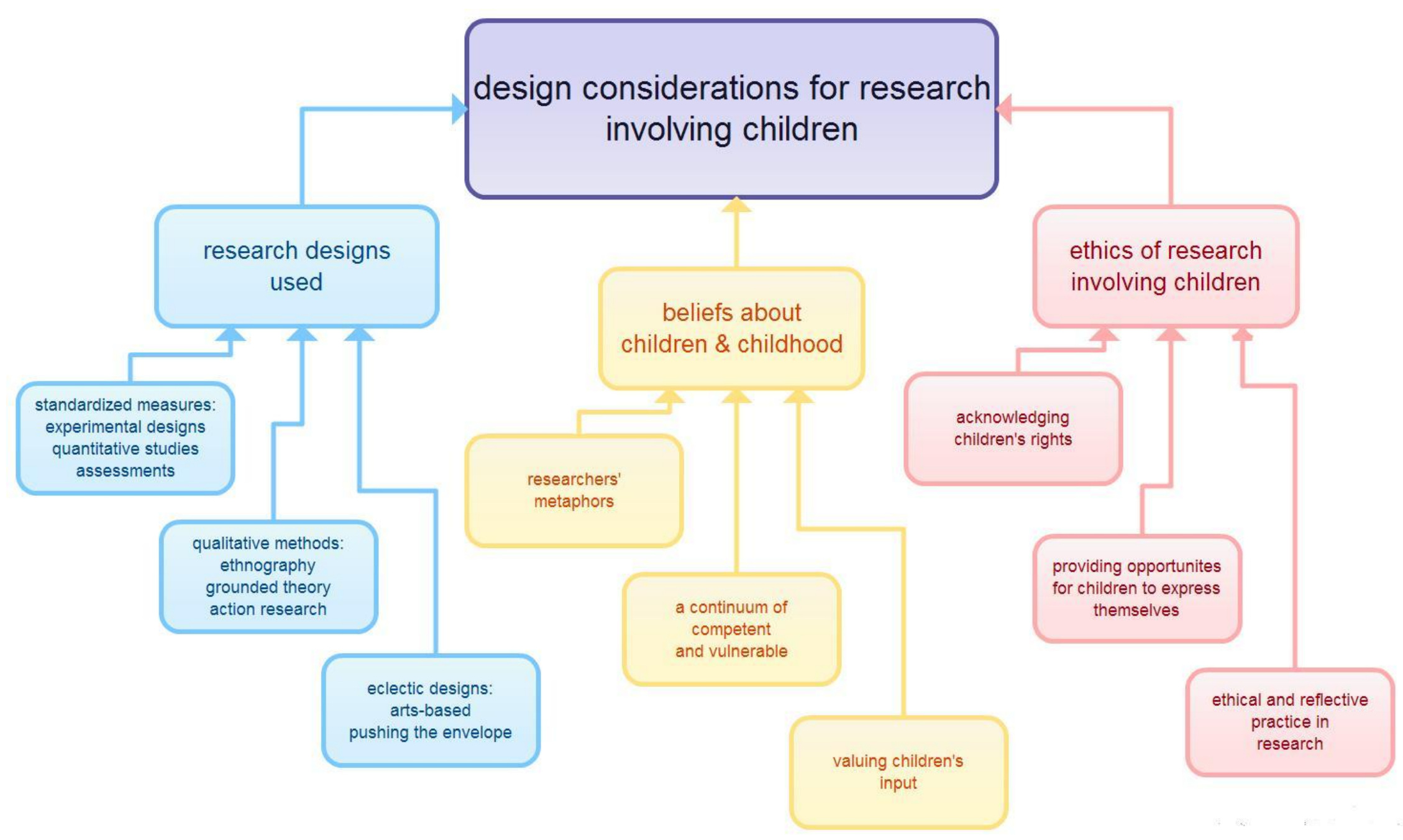




\section{Chapter 4: Findings and Discussion}

This descriptive study, while taking a primarily qualitative descriptive approach, used a mixed methods to examine which research designs contemporary Canadian researchers use in their research involving children. This approach yielded both quantitative and qualitative findings. Overall findings from the questionnaire data demonstrate that Canadian researchers use a wide range of designs when involving children in research. Additionally, findings from the interviews expand upon the range of research designs, creating a rich description of research conducted by Canadian researchers involving children. Findings are presented under four themes: Mechanisms of Engagement, Research Designs Used, Beliefs about Children and Childhood, and Ethical and Reflective Practice in Research.

\section{Mechanisms of Engagement}

During the analysis process the initial 15 categories of data collection methods listed in the questionnaire were combined into nine categories based on type of method and materials used (see Table 2). The following details first which categories of methods were reported as being used by participants, arranged from most to least frequently reported as used. Findings showed that recordings were the category most frequently reported as used, with $82 \%$ of the respondents indicating that they have used audio and/or video recordings in their research.

Observational methods was the category next most frequently reported as used. Of the 30 participants, $60 \%$ of respondents reported that they had used either participant and/or nonparticipant observations in their studies. Kinetic methods, such as tours of children's spaces, and conversational methods were the next most frequently reported categories as being used for data collection by the participants. Forty-seven percent of the respondents indicated that they had used some form of movement or tours of children's spaces as a method for data collection. 
Forty-two percent of the respondents reported that they had used conversational methods with children, which included dialogue, interviews and focus groups. Overall these findings provide insight into the most frequently used methods employed by the participants in this study. Findings show that many of the researchers who responded to the questionnaire reported that they engage children in their research by observing them in context, by talking with them about the topic of study, and by capturing data using audio and video recordings. Observation has a well-established history as a data collection method. According to Frankfort-Nachmias and Nachmias (2008), research in the social sciences has its foundation in empirical observation. Observational methods have the advantage of affording researchers direct visual contact with the event, phenomenon, behaviour or group under study. That observation was found to be such a frequently used method implies that these researchers felt it particularly suited to research involving children. Similarly, given that $47 \%$ of the participants reported using tours of children's spaces suggests that they consider it an especially appropriate data collection technique to use in research involving children. This may be based on the emerging understanding in the field of child studies that children are prone to movement, and that research that involves them directly can benefit from incorporating this understanding into a study's design. An alternative reason for the popularity of this method may be that tours of children's settings offer data that directly or indirectly relates important information regarding the topic of research, such as use of classroom spaces or what play areas are being used in children's playgrounds.

The emphasis on conversational data collection methods such as interviews and other discursive techniques suggests two possible interpretations. The first is that, given the centrality of spoken communication in human societies, researchers have a justifiable bias towards 
language-based methods of data collection. The second is that conversational data collection methods are an ideal way to elicit the information sought by researchers for their particular studies. However, results show that $83 \%$ of questionnaire respondents designed studies that involved children 0-8 years of age. Given the range of developmental levels and capabilities in this age group it is common for a significant number of children to have a developing grasp of language skills, and many may be pre-verbal. Given the small sample size in this study, it was not possible to correlate use of conversational methods with children in this age group, therefore, examining why participants reported such a high use of these methods warrants further investigation. Another question arises, regarding how children who do not communicate using spoken language, such as deaf/hearing-impaired children or children with other means of communication may be excluded from research that privileges discursive data collection techniques. This relates to literature on the topic (Clark and Moss, 2001; Dockett \& Perry, 2007; Hill, 2006; Phelan \& Kinsella, 2013; Punch, 2002), which suggests that to include pre-verbal or non-verbal children in research may mean using data collection techniques that do not rely on spoken language, such as drawing or movement-based methods.

Findings showed that the activities, arts-based, and the multi-modal categories were the least frequently used. Of the 30 participants reported by $29 \%$ as having been used, consisted of methods that were task-based and relied on text or paper and pencil approaches for collecting data. It may be that this method was so infrequently reported as being used because researchers may feel that these activities are more appropriate for adult participants, who are more likely to be able to read instructions or express themselves in writing or with text. However, it is important to note that the use of questionnaires were found to be used by over half of the respondents $(57 \%)$ in their research involving children. One reason for this may be the popularity 
of questionnaires as a method of data collection. Researchers' use of this method may be related to participants' literacy skills, with questionnaires being more popularly used with children who can read and write. On the other hand, another possibility may be that questionnaires can be adapted to include images rather than written text, and thus be made accessible to children regardless of literacy or language skill. Results show that only $28 \%$ of the participants reported using arts-based methods, and $27 \%$ reported using methods from the multi-modal category. This final category consisted of three approaches to data collection - pedagogical documentation, learning stories, and the Mosaic approach - methods which combine a variety of data collection approaches. Multi-modal approaches work to triangulate data, provide young children with accessible methods, and explicitly accommodate the multiple ways children may choose to express themselves by combining visual representation such as maps, drawings or photographs with narrative elements of data collection. Low levels of reported use of both of these categories leads to the question as to why the majority of the participants in this study have not used these methods, when a significant body of contemporary literature recommends that methods based on creative expression are particularly suitable for children. This finding may be because researchers' are not familiar with arts-based materials and techniques, or the kinds of questions and inquiry being conducted may not lend themselves to this type of approach. These eclectic approaches warrant further investigation in order to provide deeper understanding of this topic. Reported use of categories are presented in Table 3.

Within the categories discussed above, the most frequently used data collection tool indicated by this sample of respondents was audio recordings, with $90 \%$ of respondents reporting that they have used this method. The tool least frequently reported as used was dioramas, an artsbased method in which paper cut-outs are glued inside a box to construct a three-dimensional 
model. This was the only tool that none of the respondents reported using - however, one respondent did indicate that they planned to do so in the future. As discussed above, reasons for this may be that researchers found these types of data collection methods less useful than others listed in the questionnaire. Reported use of individual tools participants are detailed in Table 3.

Table 3

Reported use of data collection categories and tools

\begin{tabular}{lll}
\hline Category of method & $\begin{array}{l}\text { Participants reported } \\
\text { having used }\end{array}$ & Tool most reported as used \\
\hline Recordings & $82 \%$ & Audio recordings \\
Observational methods & $60 \%$ & Non-participant observation \\
Kinetic methods & $47 \%$ & Tours of children's spaces \\
Conversational methods & $42 \%$ & Dialogue \\
Toys and play-based methods & $38 \%$ & Puppets \\
Experimental methods & $34 \%$ & Pre-test/post-test \\
Activities & $29 \%$ & Questionnaires \\
Arts-based methods & $28 \%$ & Narratives/storytelling \\
Multi-modal methods & $27 \%$ & Pedagogical documentation \\
\hline
\end{tabular}

Throughout the questionnaire, participants were provided with opportunities to report data collection methods they used in research with children that were not included in the questionnaire (see Appendix A). The following is a brief summary of these reported methods, organized alphabetically by category. In the activities category, written semi-structured interviews were reported to have been used. Falling under the category of arts-based methods participants reported using children's books, mapping bodies and communities, making quilts, and creating wall murals. Talking circles were offered as a method in the conversational methods category. Within the category of experimental methods participants listed visual stimuli experiments, computerized measures of executive functions, verbal task assessments, and parental reporting rating scales of children's behaviour. In the kinetic methods category participants reported having conducted photovoice bicycle tours, hospital tours and body-based math activities. Supplementary toys and play-based activities reported by participants included 
playdough, Snoezelen room play, construction with blocks and wood, computerized games, marble games, balance-beams and scales for math games, and calculators. Additionally, while computer-based text activities were listed in the questionnaire in the activities category, a range of non-text-based computer activities were reported as having been part of research involving children. These included virtual online tours, radio-blogging, computer-based picture-response activities, and blogs. Respondents indicated a number of additional research designs that had not been explicitly accounted for in the questionnaire. These included correlational designs, crosssectional designs, meta-analyses, quasi-experimental designs, repeated measures designs, cohort studies, descriptive studies, health services claims analysis, a/r/tography, discourse analyses, and discursive psychology. These additions contribute to a rich description of research design used by contemporary Canadian researchers involving children in research. That such a variety exists suggests that there may not be a correct method to use in research involving children, but rather each research study should use the approach and tool that best fits its purpose. It is possible to relate this to Abbott and Langston's (2005) idea of fitness for purpose, and that the research designed to involve children requires a pragmatic approach that takes the topic of study, research questions and the capabilities of participants into consideration during the design process.

\section{Researchers' Experiences Involving Children in Research}

A thematic network analysis (Attride-Stirling, 2001) was conducted to examine contemporary Canadian researchers' design choices, as well as their experiences, that involve children in research. The global themes that emerged as part of this thematic analysis were: 1) research designs used; 2) beliefs about children and childhood; and 3) ethical and reflective practice. These global themes, and their corresponding organizing themes, are presented in the 
following section. Figure 1 (p. 38) illustrates the global and organizing themes that guided and organized the analysis.

Research designs used. Results from the questionnaire showed that a wide range of research designs are currently being used by researchers in Canada. Findings from the interviews $(n=7)$ provided a deeper understanding of these designs, as the interviewees provided a rationale for their choices, as well as background information regarding their philosophical approaches and their experiences designing research involving children. While some interviewees were found to consistently choose one design as a means of involving children, others indicated that they were more comfortable adapting the research to the needs and context of the particular study and participants, and yet others involved children in an emergent process of research design, in which methods, techniques and instruments were developed collaboratively for a specific time, place and group of participants.

Some of the researchers indicated that they used experimental and analytic research designs in their work. Dr. Lindsay discussed how she has conducted research employing a variety of approaches, including both scientific research designs and qualitative approaches. Her scientific and analytic research included secondary data analysis and cross-sectional designs to look at developmental issues to track what changes occur for children over time. She admitted to favouring correlational designs over experimental designs, making the point that cross-sectional designs could be thought of as correlational designs that correlate age with the characteristic under study. She has also conducted research that used a qualitative approach to elicit children experiences in their own voices. However, Dr. Lindsay also described how she works to fit the research design to the topic, the research question, and the context where she conducts the 
research, thus "tailoring" the methods she has used in her study to the topic and questions at hand. "It's a question of fit", she remarked, echoing Abbott and Langston (2005).

Similarly, Dr. Allison reported that she has primarily conducted meta-analytic research looking at the efficacy of mental health interventions in early childhood. In this design, children are involved chiefly as the objects or topic of study. This type of research is valuable as it contributes to advancing the body of knowledge regarding children's mental health, by contrasting a body of research findings reported in the literature across multiple contexts that focus on a particular issue. Her meta-analytic research strives to provide evidence to support claims made about attachment, ADHD, and the efficacy of early childhood mental health interventions. She stated that her impetus to conduct meta-analytic studies arises from a desire to provide evidence verifying claims made in the early childhood mental health literature. As reported by Dr. Allison, early childhood mental health interventions are often not supported by evidence, citing claims made about the efficacy of particular interventions resting on the results of a single study. She therefore conducts meta-analyses to identify a solid body of evidence to understand what works and what does not work in early childhood mental health practice. More evidence regarding which interventions are effective has the potential to change a tendency she identified in the field of early childhood mental health as "rolling back stuff that seems to work for older children and adults onto younger children.” Dr. Allison also indicated that she has conducted research that directly involved children. These studies recruited participating families from clinician's offices, schools, and learning disability associations, and involved sessions with both children and parents or caregivers. Parents were provided with questionnaires, and children were assessed through a variety of psychological tests and assessments. Such research can 
provide valuable information and affect the use of a particular intervention, or how it is understood.

Some of the research designs bridged a gulf that seems to separate quantitative research designs from qualitative research designs. Dr. Lynn conducts primarily mixed methods studies that involve children directly in the process. While she has conducted several studies using established experimental designs she reported that she felt that "doing the traditional randomized control trial approach doesn't address most of the questions I have, doesn't fit with most of the challenges that I'm faced with." Dr. Lynn therefore began to develop new ways of involving children in research. She designs participative studies that involve children's input in the development of tools that can have a significant impact on their health and well-being. Encouraging the participation of children and young people in the development of measures and tools is a key component of Dr. Lynn's research approach. She referred to this as "child-centric practice" which places the child at the centre of the research, and described the process by saying:

We take our lead from them. That doesn't mean that all the responsibility and the work is up to them, but it does mean that they need to inform and vet and validate most of what we do that involves them.

Using data collection methods that facilitate young people participation in the research process, or developing suitable tools to do so is a significant part of her work.

Furthermore, Dr. Lynn also employs an open, collaborative approach in her research design. She described an example of this approach, a study conducted in a First Nations community in Northern Ontario, in which the research team was working with community youth to develop a questionnaire to measure health and wellness. The community health centre had recently purchase bicycles for the youth centre, and the research team wanted to collect data with 
the young people in meaningful ways that also were culturally appropriate. Building on identified community strengths such as visual culture and oral tradition, a bicycle photovoice tour was developed to engage teen boy participants. In small groups led by the youth participants, research groups toured the community taking photos of what objects and places that represented health to the participants. The groups reconvened to collectively decide which photos to use and to determine the meanings of the photographs together. Placing the participants' expertise and cultural understanding at the centre of the process contributed to ensuring that the tool was relevant and reliable. Dr. Lynn's collaborative and flexible research design invites children in to participate in making the research culturally relevant and accessible, as well as involving them in developing a measure that will be used to inform their communities' well-being.

Alternatively, some researchers described only using qualitative research design. Dr. Myia characterized the research she has conducted as being primarily within the methodology of grounded theory, and discussed having used unstructured open-ended interviews, taken tours of children's spaces, and involved children in focus groups for data collection. Her area of research centres on children's outdoor play experiences, and the ways that early childhood educators can support children's outdoor play in early learning settings. By employing qualitative research designs, and by observing children within child-centric settings Dr. Myia works to establish a deeper understanding of children's outdoor play patterns. Such research allows researchers to delve more deeply into the experiences of the observed group or of the participants, focusing on context and potential interpretations of meanings and phenomena.

Dr. Finbar has a background in children's rights and working with non-governmental organizations. She has also designed qualitative research studies to conduct research that 
involves children in "consultation" processes and that most commonly take the form of focus groups. Having worked with children internationally, she discussed how research designs that used conversational methods of data collection such as interviews and focus groups emphasize the voices of children in ways that access the types of data and experiences that she is interested in investigating particularly effectively. She noted that focus groups facilitate participants' entry into the project and that everyone is "starting from the same place." They create a space where "good group dynamics can happen" and where participants have opportunities to ask questions. Dr. Finbar talked about how she particularly valued dialogue in research relationships, and appreciated how research designs that include focus groups allow for dialogue to happen in "organic ways between participants and all together in a group."

Dr. Frida and Dr. Samuel employ designs with a similar intent to that discussed by Dr. Finbar - to involve children in the research so that it is meaningful to them, so that it inspires conversation, and so that it is situated within what they know, understand and value. As an example, in one of Dr. Samuel's current projects that focuses on Francophone minority populations, he is taking an action research approach to develop an intervention or tool to facilitate communication between mothers and children experiencing domestic violence.

In the first stage of the research, which is a needs assessment, focus groups with all stakeholders [mothers, children, support/shelter workers] were used to establish what the needs are for healthy communication. The second stage, which hasn't started yet, is open - we didn't know what the children were going to tell us, what we were going to find out, so we don't know what it will be - a tool, or a programme...It will be based on their needs...

Dr. Frida has worked with a similarly emergent process in her research design. She described her research as being "with, for and by" young people. She discussed that as a novice researcher she conducted quantitative sociological research, using large-scale Canadian data sets 
and doing quantitative analysis, but that now she is much more focused on qualitative methodology, inquiring into the "life-worlds" of young people. Her phrase of "with, for and by young people" points to the collaborative and participatory nature of her research designs, in which young people are engaged as co-researchers.

It is apparent from these findings that these Canadian researchers are involving children in a broad range of research studies. Several are involving children as the object/subject or topic of study, others as participants, and yet others as co-researchers. It is evident from the findings that an equally diverse suite of mechanisms of engagement are also being used by these researchers, to engage children's perspectives, observe their behaviour and explore issues of children and childhood.

Beliefs about children and childhood. That research must be disassociated from beliefs about the topic, participants and context in order to maintain a rigorous level of validity and reliability is a core principle of quantitative research that has been challenged, particularly by qualitative research seeking to explicitly contextualize the meanings of lived experience. Findings that emerge from this study suggest that researchers' beliefs about what being a child means, what childhood entails, and what children are and are not capable of may have an impact on how research is designed.

Each participant was asked a question during the interview process regarding a metaphor or image they used to conceptualize children. Findings yielded a diverse range of images and ideas. Dr. Frida talked about how "almost nothing is the same and then some things are the same" [emphasis in original], stating that images of "abundance" and "nuance" were central to the ways that she thought about children and their experiences. Dr. Samuel stated, after a brief period of thought, "that kids are all different the same way adults are." Dr. Myia shared that 
"respect for the child and the voice of children" were her guiding ideas. "That would be my mantra," she reported. Dr. Allison quoted D.W. Winnicott, a pediatrician, who famously said "There is no such thing as a baby." Dr. Allison interpreted this to mean that a child cannot exist without caregivers, and that they cannot exist outside of a family system. It is evident from her descriptions of her family-based research that she uses this idea as a central theme in her studies. It is also indicative of her beliefs around children's autonomy and agency, which are discussed in the following section.

During the interview, Dr. Lindsay could not think of a metaphor or image that described how she conceptualized children. However, after the interview she thought of something appropriate and shared it via email. She described how a poem titled Stefan by P.K. Page (as cited in Lampert \& Gray, 2008) "resonates with me" in relation to how she thought of children.

\author{
Stefan \\ aged eleven \\ looked at the baby and said \\ When he thinks it must be pure thought \\ because he hasn't any words yet \\ and we \\ proud parents \\ admiring friends \\ who had looked at the baby \\ looked at the baby again
}

These metaphors illustrate how these researchers conceptualize children and childhood.

Some of these researchers believe children to be complicated and diverse beings who experience the world in a multiplicity of ways. Others feel that children are deeply integrated into systems that dictate their experiences and the ways they construct meaning. The following sections expand on how participants' beliefs about children and childhood influence how children are involved in their research. 
Findings from the interviews demonstrated that all seven of the interviewees talked about perspectives they and others held about children. Participants commented on popular notions held by adults, positioning children as vulnerable and needing protection. Some of the participants attributed these beliefs as having foundation in perspectives that privilege developmental understanding of childhood. For example, Dr. Allison discussed how children's abilities to assent to participation in research were different from those of adults, and that these differences influence how she approaches them in research. She questioned whether children are able to understand the greater purposes of research studies, and if their understanding is incomplete or limited, whether they were capable of authentically assenting:

Their parents understand that this is a study of attachment styles and ADHD, the kid understands that I'm going to go play with mom in this room and they're going to watch me through this mirror - they don't understand that we're looking at these issues, and they can't give any kind of consent to those specific...Those bigger picture ideas, those are completely out of their ability - of even most children through school-age...

Other findings suggest that children involved in research can be perceived as vulnerable or incompetent if the topic of the research is perceived as sensitive, emotionally charged, or deemed inappropriate for children. Four out of the seven researchers discussed how children's involvement may be influenced by the topic under study. Dr. Myia identified a "tension between adults wanting to protect children, and also wanting to give children a voice.” Dr. Lindsay reported that in her research inquiring into disliked peers in schools, schools were resistant to the research because they felt that the topic "was not conducive to a positive classroom environment", and that children were not capable of negotiating the social dynamics of naming a disliked peer and maintaining confidentiality. Dr. Samuel reported that his area of research, domestic violence and child abuse, was often considered too emotionally charged a subject for 
children, or that children didn't understand the topic. However, he reported that research involving children contradicts this. "Domestic violence research shows that kids have a different understanding of what's happening than their parents do...That parents don't think kids know what's going on - but kids do."

These negative beliefs about children's capability to "handle" a topic or the processes and contexts of research are common. Dr. Samuel also reported encountering adults or agencies who perceived children as "not capable of participating, not interested in participating, that they will be damaged" by participating in research. Dr. Lynn discussed encountering similar dynamics and negative perspectives regarding children's involvement in research, stating that "everyone is there to protect children." She discussed how notions of children's vulnerability can position research as unhealthy for children. Dr. Lynn felt that these attitudes were based on "misconceptions" about children's capabilities, as well as a lack of understanding of the value of research.

Contrasted with these views of vulnerable or incapable children, participants reported that they and others alternatively subscribed to a perspective that positioned children as capable and competent. Dr. Lindsay described how her background in developmental psychology oriented her towards a more developmental perception of children, and that she had concerns about children's capabilities being limited by their development. However, she also tried to engage children as competent informants about their own lives by positioning children as experts. This is evident in the way that she reported concentrating on informed consent. The following is an example of how she frames the idea that children are knowledgeable and reliable informants to her participants:

I'm doing a school project and I'm really trying to learn what it's like to be six and to have this stuff happen, it's been a really long time since I was six so I don't 
remember, so really, you know a lot more about this than I do, and so anything you can tell me can really help me with my project.

Dr. Lynn also demonstrated this perspective when she reported that "they have a perspective that needs to contribute to the evidence that informs care... Because they're the ones going through the surgery, so they have an opinion." It is evident from this statement that children are seen by this participant as competent beings, able to form and relate their opinion. This perspective is also evident in Dr. Frida's research. She has designed research studies that involve children as co-researchers, and that she conceives of research as primarily a "conversation" conveys that she considers what children have to say, as informants or co-designers, as worthwhile.

It is possible to re-contextualize these seemingly contrasting perspectives - on the one hand, children as vulnerable or incompetent, due to their developmental limitations or topics that are too complex or emotionally charged for them, and on the other, children as competent and active social agents who are capable of being involved in research in a wide variety of ways - by revisiting Uprichard's (2008) notion of being and becomings. By expanding the way we conceive of children to encompass both of these processes, as Uprichard discusses, it is possible to reframe the tension between these two contradictory ways of seeing into co-existing elements of childhood within the same field. This reframing is made possible when a relationship is clarified between children's vulnerability/incompetence and the maturational process of 'becoming', and when a connection is made between perceiving children as competent and the idea of a child as a social 'being'. Once these lines of connection are drawn, it is possible to see the value of both of these beliefs about children and childhood. When interpreted through a lens of children's rights, adults protecting children by controlling their involvement in research and acting as gatekeepers because of perceived vulnerability can be seen as privileging children's protection rights at the expense of their participation rights. Instead, a child-rights informed 
approach suggests that researchers encourage a climate of child involvement that considers children's participation, protection and provision rights equally.

A perspective that balances all three principles of children's rights in research is an approach that also acknowledges and validates children's input in research. The interview data indicated that all seven participants valued children's input in research, whether it was offered directly when participants were involved as informants or participants, or whether it was offered indirectly when children were the topics or objects of research. Dr. Myia described the value of exploring issues through the eyes of children, and contrasting their perspectives to get a more encompassing impression of a topic or phenomenon. By including children's perspectives of a particular event, Dr. Myia noted that we can contrast them with adult's perceptions of the same event, offering greater insight into the phenomenon as a whole. She also reported the value of children's input as a method of triangulation, providing an even richer description by including multiple perspectives. Dr. Myia reported that she spent significant amounts of time convincing adults and parents that children had "a great deal to contribute" to research. She accounted for these attitudes being based in adults' unfamiliarity with research, or a lack of understanding of the purposes of research. Dr. Finbar reported that she valued children's input as their perspectives often provide insight that would not come to light if data were only collected from adult points of view. During her inquiry into the components of child rights monitoring, Dr. Finbar collected data from adults and children internationally. The children's input provided a perspective not considered by any of the adults involved in the research, and gave Dr. Finbar deeper insight into her data.

I had all of these quantitative questionnaires, and all of these interviews, with a whole host of people from literally all over the world... and none of them talked about the importance of safety. But the young people themselves identified it as an essential component as part of monitoring young people's rights...And that is 
just incredibly significant, in terms of an essential criterion for considering the topic...A valuable piece of knowledge that I wouldn't have gotten from the questionnaires and interviews I had with adults.

Furthermore, Dr. Lynn expressed that children can often have "brilliant" input regarding the validity of a measure or the efficacy of a practice, based on their personal experience:

I've seen so many kids take really well-validated measures and point out really bizarre inconsistencies. Like, "This response set doesn't match with the question" and you look at it and you say "Ah. It doesn't!" But, it's just strictly an observation, they're not worrying about offending anybody, they're not worried about anything else, they just say what they see.

Children have a perspective that is grounded in their own experience and yet not as "filtered and sophisticated" as adults' perspectives, and can therefore offer valuable insight.

These examples demonstrate how children's input was valued by researchers, and mirrors ideas that see children as having expertise in matters that affect them. However, the interview with Dr. Allison indicates that it is not necessary to perceive children competent social agents to value their input in research. Dr. Allison discussed her views regarding children as being integrated into a family system, and thus having very little independent agency. She views children as "not at all independent, as having very little agency and very little autonomy, often to their benefit." She acknowledged that "of course, they have individual characteristics but those are so influenced by the family you grow up in, by the culture that you're in, by your society, that...To me, a child is always part of a system." This perspective does not affect the ways that she values data provided by the children involved in her research. Without this essential data she would be unable to determine whether an intervention has been effective. Dr. Allison felt that when working with young children, if researchers are able to determine ...what causes things, what leads to things and how to best help children when they're little, then that's the kind of information that's so helpful to our society as a 
whole, in terms of improving things and getting bang for buck in terms of interventions and supports.

While Dr. Allison does not see children as having agency, she still has a high regard for the data their involvement in research can provide. This is somewhat counter to a trend in contemporary research literature that claims that if research is to effectively inquire into issues of children and childhood, it is necessary to engage with children's perspectives. This counterargument is aligned with questions raised by Einarsdóttir (2007) and Spyrou (2011), who examine the centralizing of children's voices in child research with a critical view, and caution researchers to thoughtfully consider the rationale behind forefronting children's voices. It must be noted that research that does not involve children's voices can still offer valuable insight into issues related to children and childhood.

How researchers perceive the value of children's input was found to influence the roles children take in their research. The researchers interviewed were found to involve children in a range of roles in research, and some researchers involved children in multiple ways. Four out of the seven participants designed studies in which children took the role of object or subject, where children were the topic of study. Five out of the seven participants reported designing research that involved children as participants. Finally, three out of the seven participants reported having used research designs in which children took the role of co-researcher, making significant contributions to a study's design. The following describes these findings in further detail, and discusses some implications.

At one end of this range of roles, children are the topics of research. As described by Woodhead and Faulkner (2008), some studies involve children directly and position them in the role of objects or subjects of research, and others involve them indirectly as the topic of research examining issues of childhood. Findings indicated that Dr. Allison most frequently positions 
children in this role, whether she is assessing them directly in clinical research to verify diagnoses, or conducting meta-analyses of literature in which children are the topic of research. She reported that the quality of the knowledge gained by involving children as the objects or subjects of direct study was different than hearing about their behaviour and experiences from others. She stated, “there's something to be said for observation that can't be said for all the questionnaires in the world." It can be noted that by involving children in this way, Dr. Allison's research reflects her belief that children are subjects within a system that dictates much of their experience of the world.

Dr. Lindsay has also positioned children variously in both the role of subject and participant, depending on the study. In her research focusing on developmental differences, Dr. Lindsay conducted research to determine how changes over time influence children's development by comparing six year olds, ten/eleven year olds, and fifteen/sixteen year olds. In other studies, Dr. Lindsay engaged children as participants in narrative and conversational studies focused on how they understood conflict. As participants, children offered their perspectives about their experiences with conflict, which Dr. Lindsay and her research team then analyzed and interpreted from within a theoretical framework. In contrast, Dr. Myia was found to design research in which children took a more active role in participation, and were directly involved in the analysis process. Dr. Myia asked her participants to "tell me about this photo, or tell me what you see here," thereby engaging them in analysis by expressing in their own voices what the data meant. Children also took the participant's role in Dr. Finbar's consultative research approach. Her use of focus groups provided children with a forum in which they can discuss topics that she sets, but she also made space for children to explore their own ideas. She discussed how she had held follow-up meetings after a research session to explore aspects of 
what her participants were interested in, beyond the research topics discussed in focus groups. Dr. Lynn's bicycle photovoice project, described elsewhere in this paper, is another example of children taking the role of participants, informing the design and methods used in the study and assisting with the analysis process in a very active way.

While children taking a co-researcher role within a project is less common, Dr. Frida, Dr. Lynn and Dr. Samuel described this as a significant way they involved children in research. In one of Dr. Frida's current projects, a team of researchers and Indigenous children in Chile are building a school and developing a curriculum to fit the children's particular needs. The participants in this project are taking the role of "young anthropologists" and are presently collecting data and conducting observations to assess the needs of the community upon which the curriculum will be based. Similarly, a project Dr. Samuel recently completed examined Francophone children's experiences with domestic violence and related services. The first stage of the project involved children between the ages of six and eighteen who participated in focus groups to determine the scope of the research. In the second stage, based on data collected from the first, an interview process and guide were piloted with individual children. Their feedback was used to revise the research process and thus influence the remainder of the interview process. Dr. Samuel described this project as having an "open" design so as to best incorporate children's input. Dr. Samuel's initial intent was to have an advisory group of children who would be reported to at each stage of the research, but this was not possible due to logistics; therefore, a 'pilot and revise' process was a compromise arrived at once the project was underway. Both Dr. Samuel and Dr. Frida discussed how designing research that encourages children to take on this role has several challenges, from it being a time-consuming process to train children in research 
skills to experiencing significant challenges convincing agencies, funders and research ethics boards that it is worthwhile as a valuable approach.

When considering the roles that children take in research, many of the participants indicated how it depended on the type of research being conducting and the topic of study, returning to the finding that key to research design is the idea of "a question of fit" as Dr. Lindsay phrased it, or Abbott and Langston's (2005) notion of fitness for purpose. Rather than there being one correct way to involve children in research, researchers should include children as a part of the research process in a variety of ways that suit the purpose and topic of study. It seems evident from these findings that the beliefs held by these researchers about children and childhood significantly inform how they design their research. These findings also suggest that there can be no optimal way to conceptualize children - that different perspectives merely focus research on different aspects of the multi-faceted nature of children and childhood. This perspective contextualizes the value of different research designs and beliefs about children within a broader field, providing a possibility to value all with equal measure for providing significant contributions to the body of knowledge regarding children and childhood. There remains a question, however, as to how research involving children is conducted. How do beliefs about children and childhood get translated by researchers into conduct that acknowledges obligations they have to engage with children in an ethical manner? What might ethical research practice involving children be?

Ethical and reflective practice in research. Findings show that all seven participants indicated that ethics were an important consideration when involving children in research. Although five out of the seven researchers explicitly reported on the topic of gaining ethics approval from their institutions and other agencies, and reporting that it was more complicated to 
achieve for research involving children than adults. Additional findings suggest that those interviewed felt that ethical research went beyond being granted ethics approval by an research ethics board. Participants reported that involvement in research was a fundamental right of children, and that designing research that involves children is an ethical means of acknowledging children's rights. Furthermore, participants reported that their primary mechanism for acknowledging children's rights in research was by providing children with opportunities to express themselves about matters that concern them. They acknowledged the complexities of doing so, and reported that a significant complication was related to questions of power dynamics between children and adults. Finally, participants reported on how reflective practices benefit research design. Wall (2010) discusses how a childist ethics considers what obligations people have to one another.

Several of the researchers interviewed considered children's participation in research as a right to which they were entitled. Dr. Finbar stated that a primary way for researchers to respect children's human rights was by valuing children's voices and giving their opinions due weight. She reported a number of benefits attained by taking a rights-based approach to research, characterizing it as being "mutually beneficial". She explained that her position was that the researchers and participants develop a better understanding, and the studies themselves are improved, when children are recognized as rights-holders and their participation in research is valued. She further explained that by being exposed to research in which children's views and voices are valued, consumers of research come into contact with children's perspectives, which can play a role in "countering some of the misconceptions or under-appreciations of our society about what young people... are capable of." This finding is supported by notions put forward by 
Warin (2011) and Phelan and Kinsella (2013), who argue that children's involvement in research can influence popular ideas of children's capacities.

Dr. Samuel also reported taking a children's rights perspective regarding research design, stating that children have a fundamental right to participate in research. He noted that while including them is justifiable in terms of good scholarly outcomes, researchers also need to acknowledge that children are entitled to participate in research that will have an impact on their lives, and thus participate in the decision-making processes that affect them. He said researchers “shouldn't do it just because we'll get a better understanding, we should do it because children have a right [to be involved]." Similarly, Dr. Lynn reported the necessity of acknowledging the value of children's rights in health research, and that:

The main focus of putting the child at the centre is to empower them - their health is their responsibility...We expect them to do different therapies...do different exercises...change their behaviours like not smoke... Why wouldn't they be part of the measurement process?

It is evident from these examples that acknowledging children's rights to participate in research and designing research that incorporates children's perspectives is an ethical stance taken by several of these researchers. This stance is reflective of positions put forward in the literature that view children as rights-holding citizens. Broström (2012) regards the perspective of children's rights as an integral part of ethical research. Pascal and Bertram (2009) state that an ethical commitment to research aims to empower children by involving them in the research process. Findings from this study indicate that a concrete way researchers acknowledge children's rights was by providing children with opportunities to express their opinions and have their views taken seriously.

Of the seven researchers interviewed, six reported that presenting children with these kinds of opportunities was a dimension of ethical research. Dr. Myia identified that her primary 
ethical concern when involving children in research was that "their voice gets embedded in the research". Similarly, Dr. Finbar reported that in her focus group approach to consultation with children, data expressed in different modalities such as diagrams or other visual representations of ideas are welcome. She felt that this was an important way to ensure that "young people were encouraged to contribute in whatever way they felt appropriate." Dr. Samuel also noted that he felt it was vital to involve children in research as a way to acknowledge the value of their ideas and voices, as they are "competent and complete social agents with voices, opinions and ideas of their own that have value." By not involving children in research that investigated their experiences, Dr. Samuel felt that researchers would be in danger of imposing their own interpretations on children's experience, which may or may not be correct, as discussed in Punch (2002). If children have an opinion, and a right to express it, Dr. Samuel suggested that ethical research practice called for children to be involved.

Dr. Lindsay reported that much of her research also involved children having an opportunity to express themselves, as a key component of her research regarding their moral understanding of conflict, as it allowed her to analyze how children construct meaning about their experiences. She discussed the importance of being able to contrast children's different perspectives, especially about the same event, describing it as "the meat and potatoes of what we're looking for" in her studies. She also maintained that adults often neglect to include children in decision making that directly affects them, and that research has the potential to be a forum for such consultation. "We talk a lot about social problems that we are trying to solve for kids, but I think sometimes we forget to ask children's perspectives about those issues," suggesting that providing children with opportunities to share their perspectives and become involved in process that shape their lives would be beneficial. Therefore, it can be seen that 
empowering children by providing them with opportunities to have their opinions valued and incorporated into research was perceived by these researchers as a powerful means of ethically involving them in the process. It is evident that providing children with opportunities to share their perspectives relates directly to children's rights.

Furnishing children with opportunities to share their perspectives relates to beliefs researchers have about children being competent citizens, as well as to issues taken up in the literature regarding the value of children reporting on children's issues. Tangen (2008) describes this as children's insider perspective, Christensen (2004) and Broström (2012) among others, also discuss children as experts in matters regarding childhood. Recognizing that children have something of value to share, and designing research so that this is possible indicates that researchers are considering what obligations they may have to children by including them in research that concerns them.

Participants reported that providing children with such opportunities was not always a simple task. Issues and tensions were found to complicate children's involvement in research, and participants reported that particular attention needed to be paid to how power dynamics influence adult-child relations in research. Findings demonstrated that this attitude was evident among several of the researchers interviewed. Dr. Lynn discussed that making intentional decisions about how to work with power dynamics in the research design was a key element of ensuring that children's participation in research was voluntary and authentic. This was evidently a common concern, as six out of the seven participants reported that issues of consent and assent were related to power dynamics in research. Furthermore, Dr. Lynn felt it important that researchers make intentional decision towards equalizing or inverting the power between children and adults within a research relationship, saying: 
Children look to adults thinking that we can tell them the answers, and often we're looking to the children to tell us the answers, but history dictates that we are the experts...You have to think about how to reverse that power dynamic...Let them know that yes they're in control and yes you're willing to follow.

With young children, a concrete way that Dr. Lynn works to invert power dynamics is to "put kids in a chair and then I'll sit on the floor...Just to give them cues that they're in a position of power." Describing it as a central part of child-centric methods, she noted "they don't always have to be in power, but they have to be on at least equal footing, or all they give you back is what they think you want to hear." Although she acknowledged that all research needs to take power dynamics into consideration, she felt that these dynamics are emphasized in research involving children given how children are particularly marginalized. Children's biological immaturity and their differences in size and experience magnify power differentials already present in social relations.

This power differential between adults and children was remarked upon by several other participants. Dr. Myia reported that it was important for researchers to frame their research so as to empower the children they worked with, especially if they were part of communities or populations that were marginalized in society. Dr. Frida also commented on the ways that power needs to be negotiated when involving children. While she did not feel as though children were "necessarily disempowered, or less, or in a different place", she did feel that in many contexts, and especially schools, there exists another layer of power dynamics that need to be taken into consideration. The way that Dr. Samuel and Dr. Lindsay reported that they position children as experts in matters that affect them, discussed in the previous section, were also findings that address power differentials between adults and children. It is evident from these examples that, for the participants of this study, ethical research requires that adult researchers contend with issues of power intentionally. 
This perspective is reflective of the ways that Conroy and Harcourt (2009), Lundy, McEvoy and Byrne (2011), and Spyrou (2011) call on researchers to pay attention to how they take up issues of power when involving children in their research, and to reflect on how power has influence over how children's voices are valued in research. Findings demonstrate that several of the participants are engaged in this kind of reflection. Both Dr. Lynn and Dr. Lindsay have developed concrete strategies to let children know they are power-holders within the research relationship, and that their opinions have weight and merit. Additionally, Dr. Frida and Dr. Samuel deliberately put children in roles where they share power with researchers, also discussed elsewhere in this paper. It is not being suggested that if research is designed so that power is not being shared directly with children, such as in cases in which children are the topics of research but not immediately engaged in the process, it is automatically unethical. Rather, the point that these findings present is that ethical research must deliberately consider questions of power. If a study involves children indirectly as the topic of study, it may be ethical practice to consider how power relates to that topic. Abbott and Langston's (2005) notion of fitness for purpose once again can be applied - tailoring discussions of power to the manner in which children are involved in a study to fulfil ethical requirements.

The role of reflection in ethical research requires some discussion given the design of the present study. As part of the 'member checking' process, the researcher asked the participants a final question (via email) regarding what benefits they felt might be gained by participating in a reflective project regarding their research. Of the seven participants, five responded to this question. Several of the researchers reported that they valued having an opportunity to reflect on their research as they gained insight about their research as they discussed their work, and that putting their thoughts into words helped clarify their ideas. Dr. Myia reported that, 
Sometimes we can become isolated and therefore neglect to really ask what are we doing, why are we doing it, and is it the best way to do it. So, of course, being involved in your project required me to take stock of my practice, and how I share information about research with new researchers.

Dr. Frida shared that reflecting on her research she found that she was "trying to articulate what is often not spoken", and that this was "useful and important" to her as a researcher.

Communicating about a topic involves organizing information and determining what is important and what is not. It is evident that these researchers valued the reflective opportunity to revisit and rearticulate their approach to research. Dr. Allison reported that the reflective process of this study allowed her to:

...reflect on my assumptions, which is always nice to do as these things become standard to one after you do them for a while and you no longer stop and consider why you do things the way you do or whether there is a better way.

In this instance, reflection offered the researcher an opportunity to re-evaluate her methods and approaches. Dr. Lindsay was found to have a similar response, describing two reasons to reflect on research:

First, sometimes the choice of a particular design can become a sort of habit, and so it's important to remain thoughtful about selecting the best design to answer the question you are trying to ask (rather than the most convenient or familiar one). Second, I think in general it is important to "check in" with yourself to make sure that your studies are in line with your own values (e.g., that they respect children's voices), and reflecting thoughtfully on your methods is one important way to confirm this.

This "check-in" process to ensure that a researcher's methods and designs are thoughtfully aligned with their values makes evident the connection to researchers' reflective practice and ethical practice in research. Dr. Samuel reported that, "it was an opportunity to take some time to think globally about the work I have done with children and young people," relating that participating in the reflective process in the present study was a valuable 
experience, as it allowed him to take an overall perspective and examine the challenges and opportunities in his research.

Many of these observations are in accordance with Phelan and Kinsella's (2013) discussion regarding reflective practice as a tool for ethical research. Findings from the current study, that reflection supports researchers' abilities to think critically and communicate about their research practices, is supported by the work of Phelan and Kinsella. They also provide support for the claims made by the researchers interviewed that reflection encourages a "global" perspective, allowing researchers to situate their struggles within a larger context of research involving children. Finally, the finding that reflective practice helped participants maintain a connection between their research design and their beliefs and values regarding children and childhood was central to Phelan and Kinsella's argument that reflective practice is a powerful instrument in creating ethical research.

Furthermore, these findings bring to light important questions. Are there universal principles that must be adhered to in every study, or are ethical practices situated in context, when trying to define ethical research involving children? Phelan and Kinsella claim that ethical practice is contextualized in the daily lived experience of a research context. Wall contends that there are essential elements that lie at the root of ethics in the light of childhood. Given the scope of this major research paper, the intent here is not to resolve these questions, but to engage with them, and potentially point in a direction of further questioning and research. 


\section{Chapter 5: Conclusion}

Overall, this study presents findings that show that Canadian researchers who involve children in research do so by using a variety of research designs. A wide range of quantitative, qualitative, mixed methods, and more eclectic approaches are being applied to issues of children and childhood across the country and in many different disciplines. Canadian researchers participating in this study hold an equally wide range of beliefs about children and childhood, and the ways that these beliefs influence research design was explored. Finally, the obligations researchers have to children regarding ethical involvement in research were found to be a concern for the Canadian researchers involved in this research project.

\section{Implications for Practice}

Two implications for practice emerged from this research project. The first is that there is no one-size-fits-all design for research involving children that suits every purpose of possible research. Each study is considered from the perspective offered by the idea of fitness for purpose and must be tailored to suit the particular constellation of topic, questions, participants, and context. To do so, this study suggests that researchers consider research approaches, conceptualizations of children and childhood, and mechanisms of engagement as options to choose from within a broad field or continuum, or as points within a constellation, rather than as oppositional and antagonistic camps in the battle of research. The second implication for practice is that researchers are encouraged to use reflection, deliberately and continuously in all parts of the research process, as a tool to make the ways that they involve children more ethical. By intentionally engaging with questions regarding the topic and purpose of a particular study, who will benefit from the research, and how issues of power and children's rights can be a part of 
every aspect of research, reflective practice is recommended as a means for researchers to improve as practitioners.

\section{Limitations}

This study was constrained by several limitations. First, the questionnaire was a nonstandardized instrument developed by the researcher for the purpose of this study. Therefore, it is limited in its scope in regards to its reliability and validity. In retrospect, it was found that several of the questions could have been reframed to provide definitions and to minimize overlapping data. The 30 respondents completed the questionnaire with few questions or complaints, which suggests that it was considered comprehensible by participants; however, further piloting would be necessary for future research studies.

Second, the small sample size made the randomization of potential interview participants a challenge. Given that there was only one participant in some of the departments meant that those researchers were targeted as interview participants, while respondents in other departments with higher numbers were not targeted and selected at random.

Finally, given that the interviews were not conducted face-to-face, the researcher acknowledges that data may have been lost due to the lack of visual cues such as body language and facial expressions. The researcher worked to contend with this limitation by employing attentive and active listening techniques, and by asking questions when clarification was required.

\section{Recommendations for Future Research}

Several suggestions for directions of future research emerged from this study. Further research into how children are involved in Canadian research is recommended, so that a broader and more detailed understanding of how such research is being conducted can be developed. It 
was not within the scope of this research study to explore the question of why researchers appear to be hesitant to use data collection methods based on creative expression, even though there is much support for it in the body of literature, and further research in this direction is suggested. Furthermore, the apparent divide between the arts and the sciences mentioned in this study, and their relationship to research involving children bears further investigation. Finally, questions were raised regarding a universal or contextual nature of an ethics of research involving children, which could be a fruitful course of future study. The aim of this study was to address a gap in the conversation regarding how Canadian researchers involve children in research. This study concludes as the beginning of this conversation. 


\section{Appendix A: Research Methods for Involving Children - Questionnaire}

\section{Research Methods for Involving Children}

Which research methods have you used in research that involves children? (please check the box which most closely matches your experience.) It is suggested that respondents make a quick scan of all the categories listed before responding, as a method they may think to list in one category may appear in another further along in the questionnaire.

A. Activities/Exercises

Have used Have not used Plan to use

1. Sorting activities
2. Matching activities
3. Worksheet-style activities
4. Questionnaires

7. Please indicate any other types of activities used in your research that involves children:

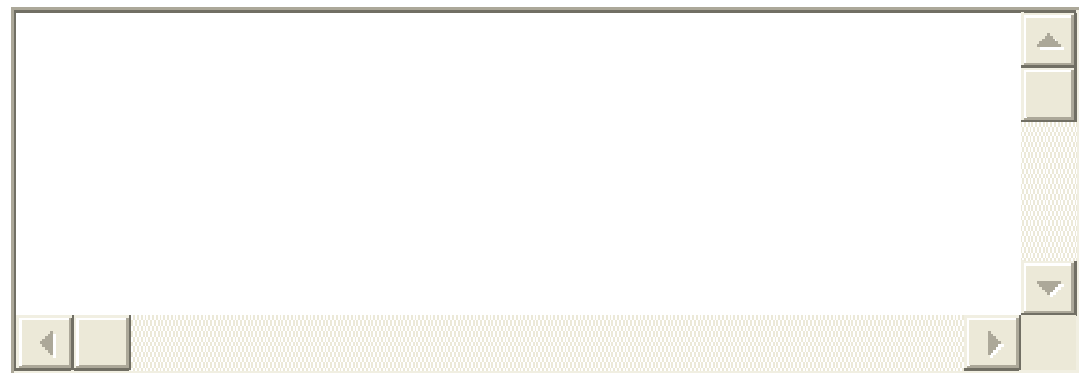


B. Experimental Design

Have used Have not used Plan to use

8. Pretest/Postest

c

c

c

9. Experimental/Control Group

$c$

$c$

c

10. Please indicate other experimental designs used in your research that involves children:

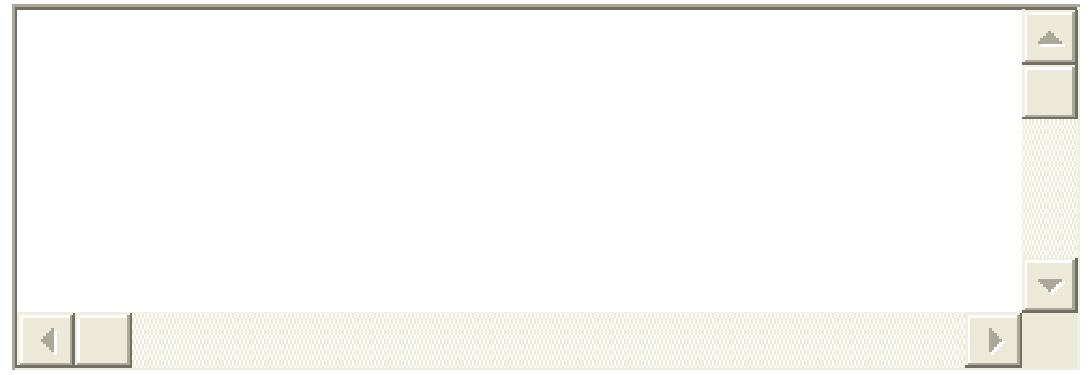

C. Focus Groups

Have used Have not used Plan to use

11. With 2-3 children

$r \quad r$

12. With 3-5 children

$0 \quad 0$

13. With 5-10 children

C

c

$c$

14. With over 10 children

C

c

c

D. Conversations

Have used Have not used Plan to use

15. Dialogue

C

c

$c$ 
E. Kinetics

Have used Have not used Plan to use

16. Tour of children's spaces

r

c

$c$

17. Please indicate other types of kinetic research methods not listed here:

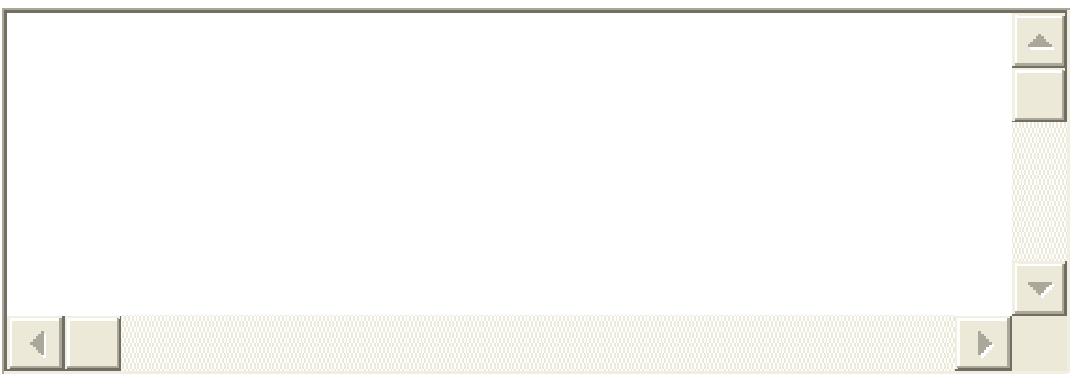

F. Interviews

Have used Have not used Plan to use

\begin{tabular}{|c|c|c|c|}
\hline 18. Structured & $c$ & $c$ & $c$ \\
\hline 19. Semi-structured & $c$ & $r$ & $r$ \\
\hline 20.Unstructured/open-ended & $c$ & $r$ & $r$ \\
\hline
\end{tabular}

21. Please indicate other types of interviews used in your research that involves children:

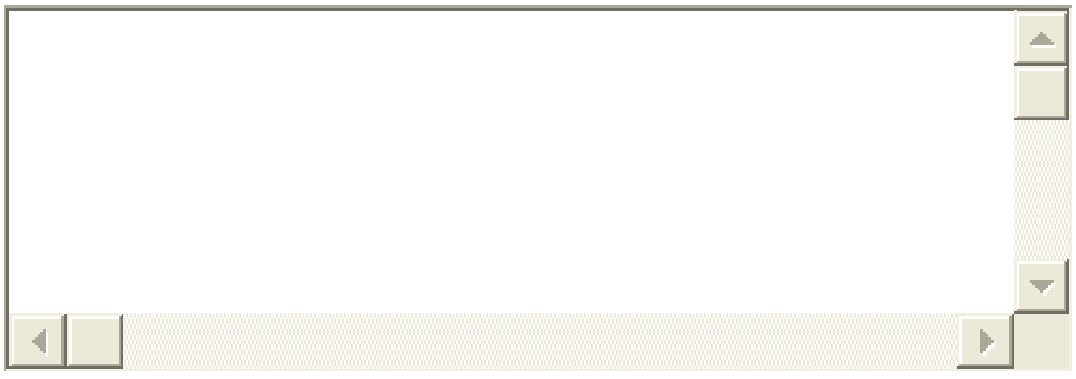


G. Observation

22. Participatory Have used Have not used Plan to use

23. Non-participatory

$c \quad c$

$c$

24. Please indicate other types of observations used in your research that involves children:

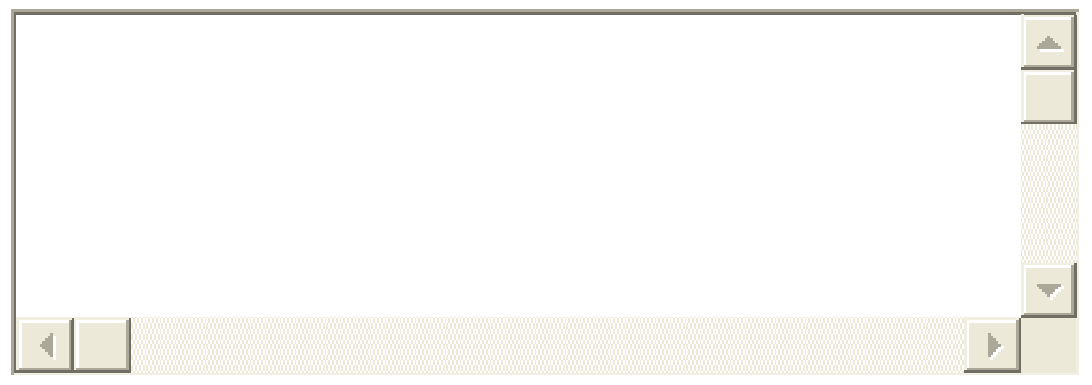

\section{H. Performance}

\section{Have used Have not used Plan to use}

25. Dramatic re-enactment

r o

26. Role-play

$0 \quad 0$

27. Narratives story-telling

$0 \quad 0$

28. Gesture/gestural movement

(use of gesture/movement

$0 \quad 0$
vocabulary)

29. Tableaux-vivant/human sculptures, etc.

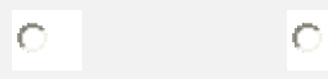

$c$ 
30. Please indicate other types of performances used in your research that involves children:

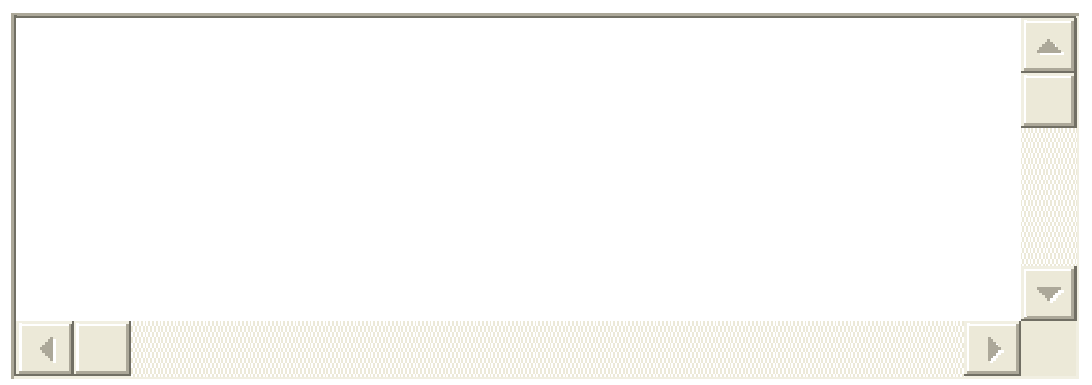

I. Photography

Have used Have not used Plan to use

31. Photographs (produced by participants)

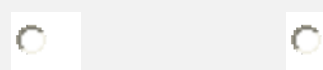

$c$

32. PhotoVoice

$c \quad c$

$c$

33. Fotonovela (visual narrative combining photograph, story and

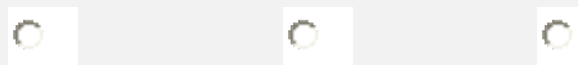
performance)

34. Image collection

$c \quad r$

$c \quad c$

35. Please indicate other types of photography used in your research that involves children:

4

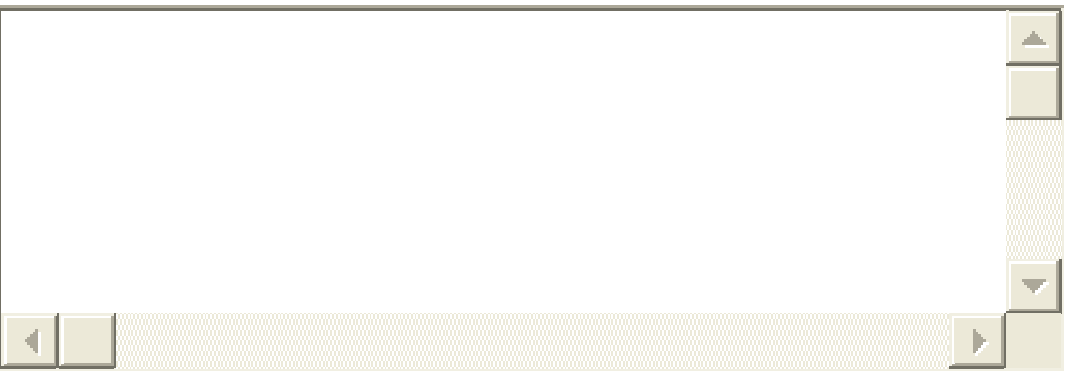




\section{J. Pictures}

36. Found photographs
37. Illustrations
$\begin{gathered}\text { 38. Images not created by } \\ \text { children (commercial) }\end{gathered}$

39. Please indicate other types of pictures used in your research that involves children:

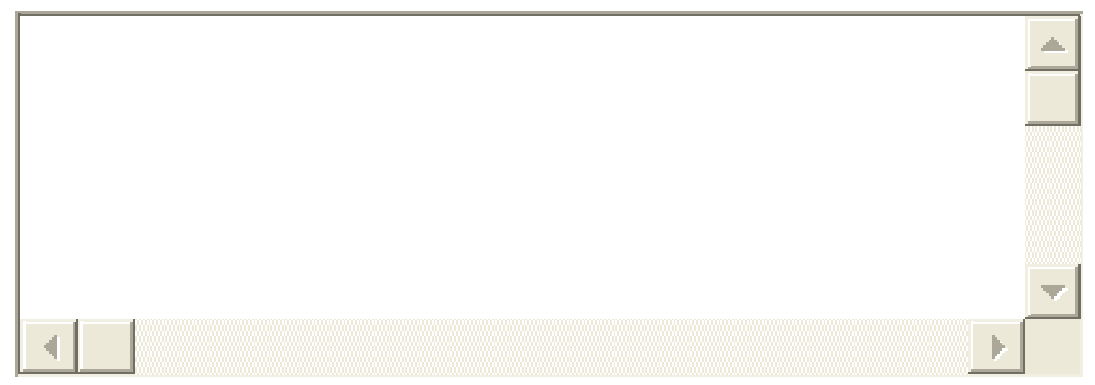

\section{K. Sculpture}

Have used Have not used Plan to use

40. Sculpture $\quad \mathrm{C}$

41. Diorama (model using paper cut-outs, viewed from one perspective)

42. Model-making (threedimensional sculpture of place C C $C$ or situation) 
43. Please indicate other types of sculpture used in your research that involves children:

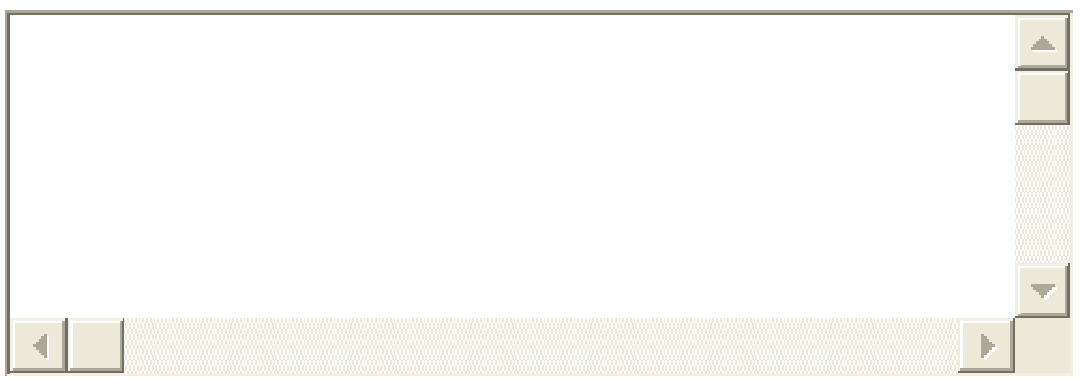

L. Standardized children's measures

44. Please list standardized measures that you have used in your research that involves children:

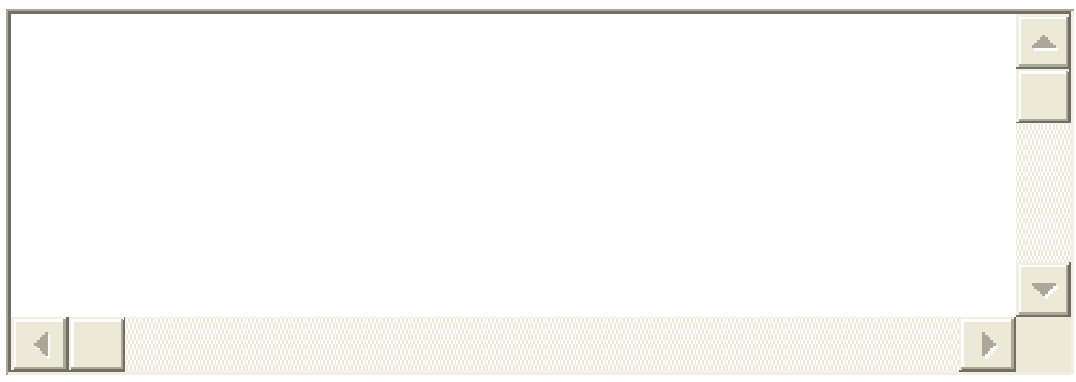

45. Please list standardized measures that you intend to use in your research that involves children:

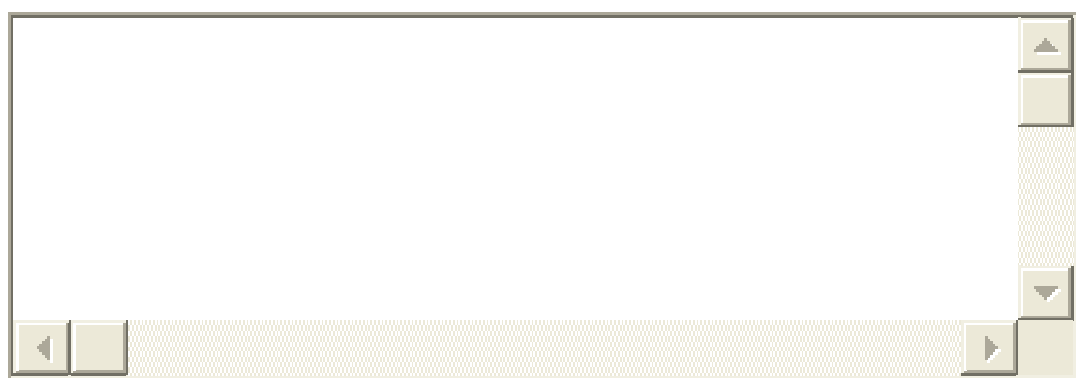


M. Toys/Games

\begin{tabular}{|c|c|c|c|}
\hline & Have used & Have not used & Plan to use \\
\hline 46. Dolls & $c$ & $c$ & $c$ \\
\hline 47. Puppets & $C$ & $r$ & $r$ \\
\hline $\begin{array}{r}\text { 48. Games (board games, } \\
\text { movement games) }\end{array}$ & $r$ & $c$ & $c$ \\
\hline
\end{tabular}

49. Please indicate other toys/games used in your research that involves children:

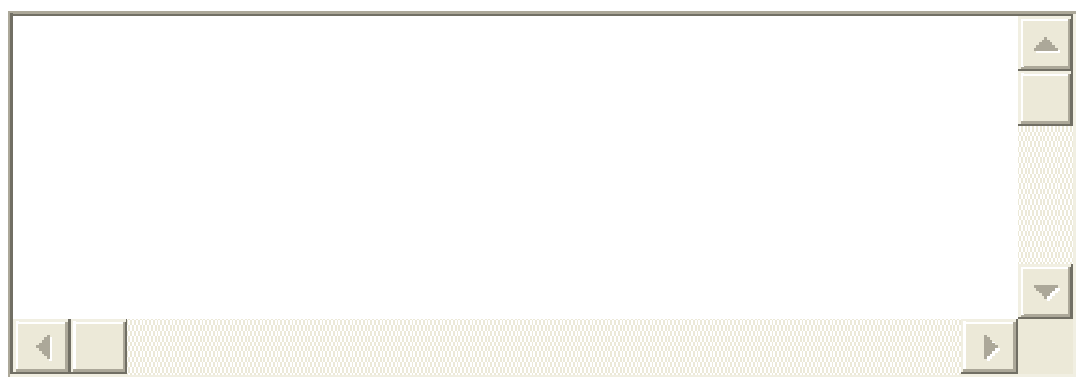

N. Recordings

\begin{tabular}{llll} 
& Have used Have not used Plan to use \\
50. Audio & 51. Video & $C$ & $\mathrm{C}$ \\
\hline
\end{tabular}

52. Please indicate other types of recordings used in your research that involves children:

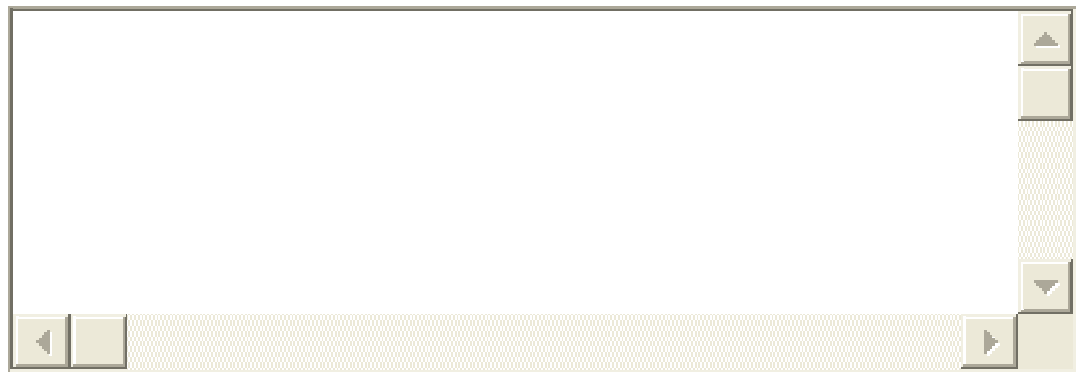


O. Visual Media

\begin{tabular}{llll} 
& Have used & Have not used Plan to use \\
53. Drawing & 54. Painting & $c$ & $\mathrm{C}$ \\
55. Collage & $\mathrm{C}$ & $\mathrm{C}$ \\
\hline
\end{tabular}

56. Please indicate other forms of visual media in your research that involves children:

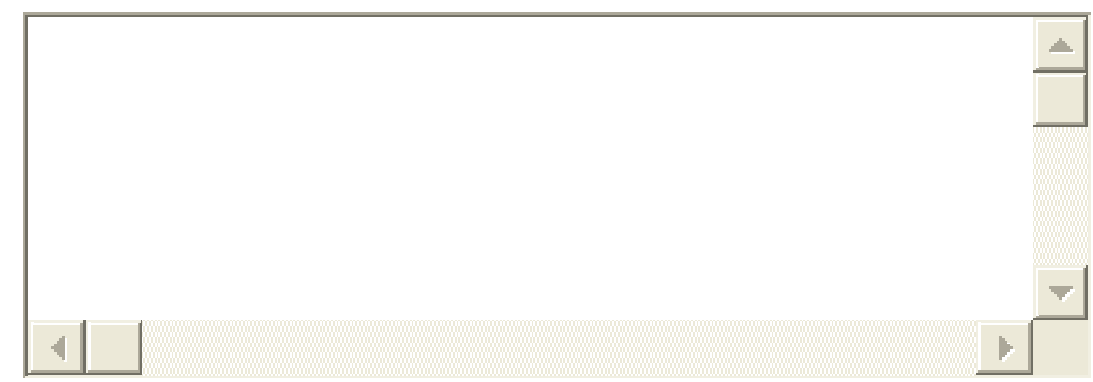

P. Multi-modal/Mixed approaches

These data collection approaches integrate several methods into a structured whole

Have used Have not used Plan to use

57. Pedagogical documentation

$r \quad r$

58. Learning stories

C

$c$

$r$

59. Mosaic approach

$r$

$r$

$r$ 
60. Please indicate other multi-modal or mixed approaches you have used in your research that involves children:

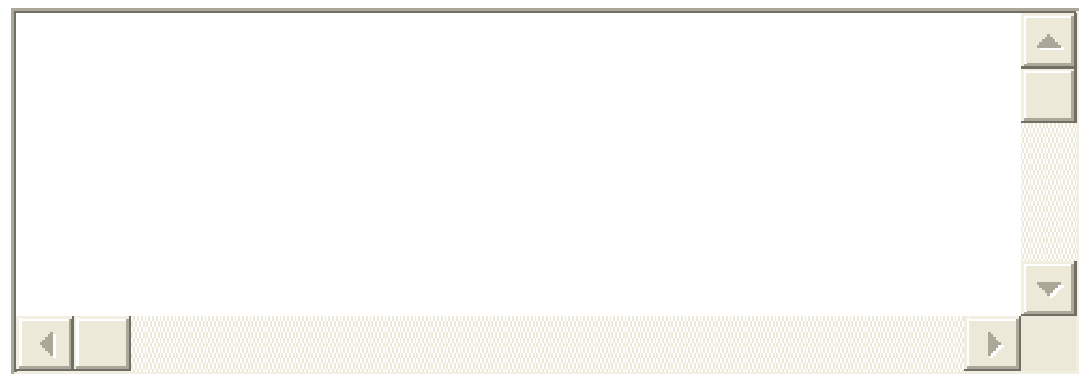

Q. Other

Please describe any other methods that you have used in your research that involves children:

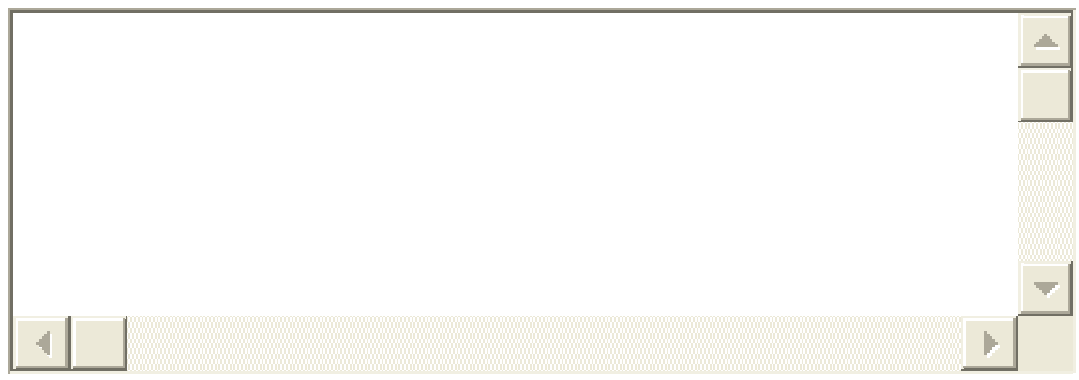

\section{Demographic information}

At present, I am a:

- $\Gamma$ Faculty member

- $\Gamma$ Retired faculty member/researcher

- $\Gamma$ Graduate Student

- $\Gamma$ Retired researcher

- $\Gamma$ Researcher working with children

- $\Gamma$ Professional 
How many years of experience do you have conducting research involving children?

- $\Gamma$ Under 1 year

- $\Gamma$ 1-2 years

- $\Gamma$ 3-5 years

- $Г$ 6-9 years

- $\Gamma$ 10-14 years

- $\Gamma$ 15-20 years

- $\Gamma$ Over 20 years

What is your highest level of education?

- $\Gamma$ University undergraduate degree

- $\Gamma$ Postgraduate degree:

- $\Gamma$ Master of Arts

- $\Gamma$ Master of Education

- $\Gamma \mathrm{PhD}$.

- $\ulcorner$ Ed.D

In what discipline? (e.g. Early Childhood Studies, Social Work, Education, etc.) Do you have a professional designation? (e.g. RECE)

Please use this space to explain any of your answers:

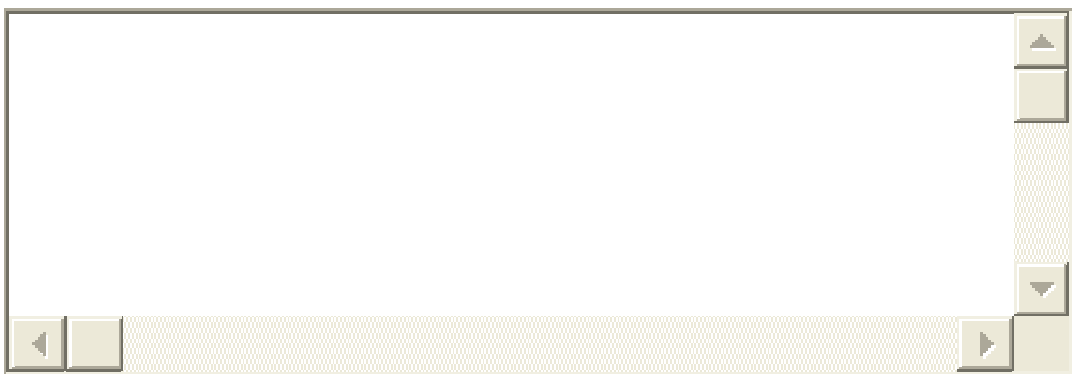


What is your current job title?

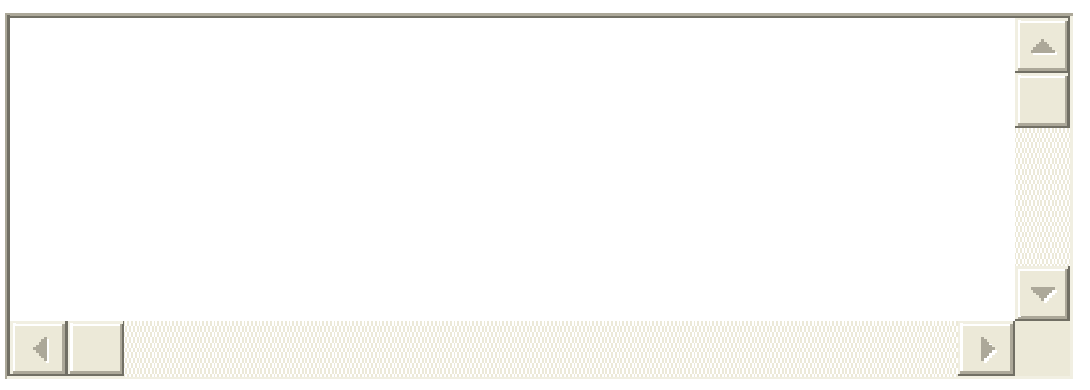

Please tell me about your research practice

1. Why do you conduct research that involves children?

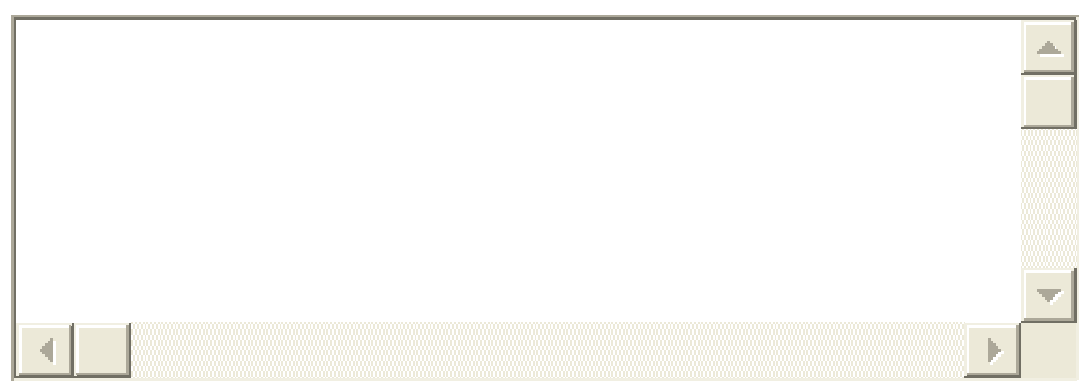

2. Please give examples of the ways that children have participated in your research.

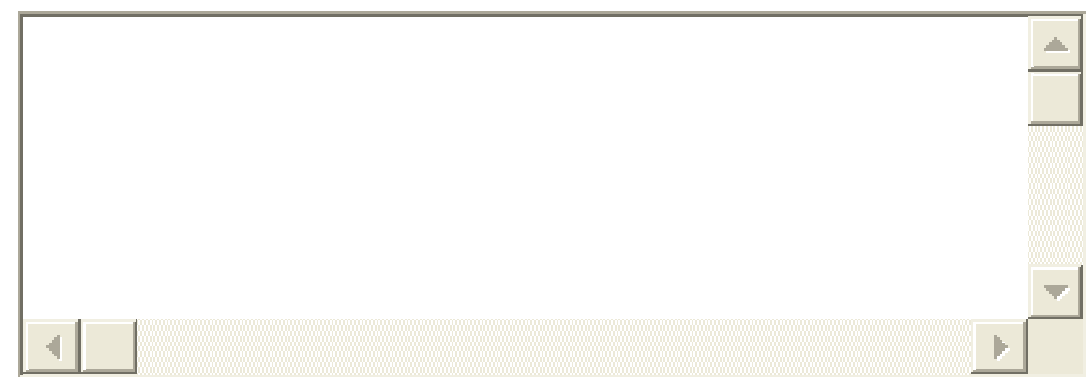

3. Why did you choose the research methodologies you did in your research involving children?

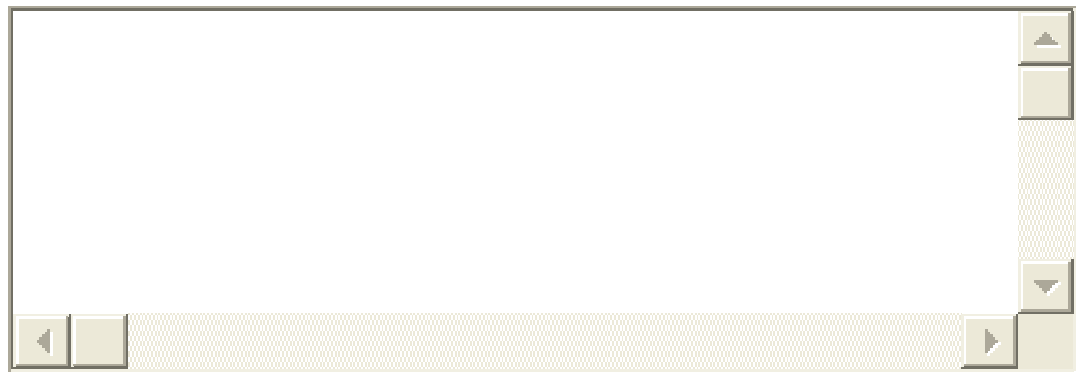


4. What language(s) do you conduct your research involving children?

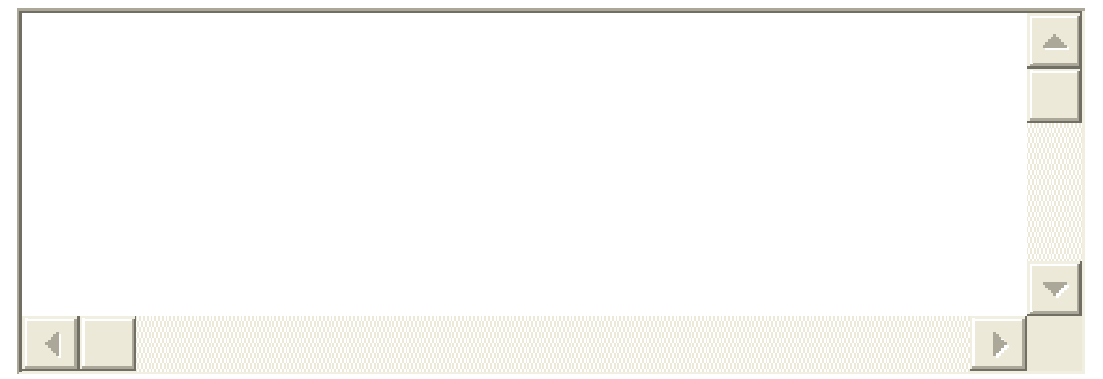

5. Where (e.g. urban areas in Canada, rural areas in other countries) and in what type(s) of settings do you conduct your research involving children?

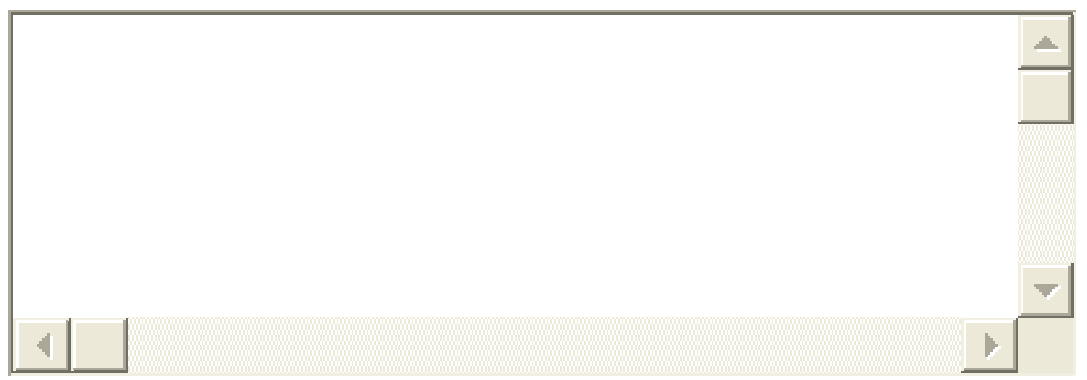

What are the age range(s) of the children that you involve in your research?

- $\Gamma$ early childhood (0-8 years of age)

- $\ulcorner$ middle childhood (5-12 years of age)

- $\Gamma$ older childhood (10-13 years of age)

- $\Gamma$ adolescence (12-15 years of age)

- $\Gamma$ youth (13-18 years of age)

Name: * Your name will be coded during data analysis, and is only requested here for the purposes of data organization

(C) Noah Kenneally, 2013 


\section{Appendix B: Semi-structured Interview Guide}

1. Please describe the research you have done/are doing that involves children.

a. In the context of your discipline, do you conduct traditional research involving children - different things that you do uniquely?

2. How would you characterize the research designs you have used in this research?

3. How did you collect data?

4. What tools/measures have you used?

5. Do you think that research that involves children is the same or different than research involving adults? Why?

6. Please identify some of the challenges you have encountered when including children in your research.

7. Are there barriers to involving children in research in your work/in your discipline/in Canada?

8. What are the benefits of involving children in research?

9. Further ethical issues?

10. Further stories?

11. How would you describe the way you conceptualize children - metaphor or image.

12. Publication that might exemplify your research approach involving children?

(C) Noah Kenneally, 2013 


\section{References}

Abbott, L., \& Langston, A. (2005). Ethical research with very young children. In A. Farrell (Ed.), Ethical Research with Children (pp. 37-48). Berkshire, UK: Open University Press.

Attride-Stirling, J. (2001). Thematic networks: an analytic tool for qualitative research. Qualitative Research, 1(3), 385-405.

Baker, R., Panter-Brick, C., \& Todd, A. (1996). Methods used in research with street children in Nepal. Childhood, 3(2), 171-193.

Barnett, W. S., Jung, K., Yarosz, D. J., Thomas, J., Hornbeck, A., Stechuk, R., \& Burns, S. (2008). Educational effects of the Tools of the Mind curriculum: A randomized trial. Early Childhood Research Quarterly, 23(3), 299-313.

Broström, S. (2012). Children's participation in research. International Journal of Early Years Education, 20(3), 257-269.

Cachia, M., \& Millward, L. (2011). The telephone medium and semi-structured interviews: A complementary fit. Qualitative Research in Organizations and Management: An International Journal, 6(3), 265-277.

Carlson, J. A. (2010). Avoiding traps in member checking. The Qualitative Report, 15(5), 11021113.

Case, R. (1991). Stages in the development of the young child's first sense of self. Developmental Review, 11(3), 210-230.

Christensen, P. H. (2004). Children's participation in ethnographic research: Issues of power and representation. Children \& Society, 18(2), 165-176. 
Christensen, P. H., \& James, A. (2008). Introduction: Researching children and childhood cultures of communication. In P. H. Christensen \& A. James (Eds.), Research with Children: Perspectives and practices. New York, NY: Routledge.

Clark, A., \& Moss, P. Listening to Young Children: the Mosaic approach. London, UK: National Children's Bureau.

Conroy, H., \& Harcourt, D. (2009). Informed agreement to participate: Beginning the partnership with children in research. Early Childhood Development and Care 179(2), 71-78.

Creswell, J. W. (2009). Research Design: Qualitative, quantitative and mixed methods approaches. Thousand Oaks, CA: Sage.

Dalli, C., \& Te One, S. (2012). Involving children in educational research: researcher reflections on challenges. International Journal of Early Years Education, 20(3), 224-233.

Denzin, N. K. (2012). Triangulation 2.0. Journal of Mixed Methods Research, 6(2), 80-88.

Dockett, S., \& Perry, B. (2007). Trusting children's accounts in research. Journal of Early Childhood Research, 5(1), 47-63.

Dockett, S., Einarsdóttir, J., \& Perry, B. (2009). Researching with children: ethical tensions. Journal of Early Childhood Research, 7(3), 283-298.

Dockett, S., Einarsdóttir, J., \& Perry, B. (2012). Young children's decisions about research participation: Opting out. International Journal of Early Years Education, 20(3), 244256.

Einarsdóttir, J. (2007). Research with children: methodological and ethical challenges. European Early Childhood Education Research Journal, 15(2), 197-211.

Ellingson, L. L. (2009). Engaging crystallization in qualitative research. Thousand Oaks, CA: Sage. 
Englander, M. (2012). The interview: Data collection in descriptive phenomenological human scientific research. Journal of Phenomenological Psychology, 43(1), 13-35.

Fisher, M. J., \& Marshall, A. P. (2009). Understanding descriptive statistics. Australian Critical Care, 22(2), 93-97.

Flick, U. (2007). Designing qualitative research. London, UK: Sage.

Freeman, M., \& Mathison, S. (2009). Researching children's experiences. New York, NY: Guildford.

Frankfort-Nachmias, C., \& Nachmias, D. (2008). Research methods in the social sciences. New York, NY: Worth Publishers.

Goodwin, W. L., \& Goodwin, L. D. (1996). Understanding Quantitative and Qualitative Research in Early Childhood Education. New York: Teacher's College Press.

Greene, S., \& Hogan, D. (2005). Researching Children's Experience: Approaches and methods. London, UK: Sage.

Grieg, A., Taylor, J., \& MacKay, T (2007) Doing Research with Children. London, UK: Sage.

Guillemin, M., \& Gillam, L. (2004). Ethics, reflexivity and ethically important moments in research. Qualitative Inquiry, 10(2), 261-280.

Hill , M. (2006) Children's voices on ways of having a voice: Children's and young people's perspectives on methods used in research and consultation. Childhood, 13(1), 69-89.

Hill, M., Laybourn, A., \& Borland, M. (1996). Engaging with primary-ages children about their emotions and well-being: Methodological considerations. Children \& Society, 10(2), 129144. 
Hogan, D. (2005). Researching 'the child' in developmental psychology. In S. Greene \& D. Hogan (Eds.), Researching children's experience: Approaches and methods. Thousand Oaks, CA: Sage.

James, A., Jenks, C., \& Prout, A. (1998). Theorizing childhood. Cambridge, UK: Polity Press.

Kail, R. V., \& Zolner, T. (2009). Children: A chronological approach, $2^{\text {nd }}$ Canadian Edition. Toronto, ON: Pearson Prentice Hall.

Kirova, A., \& Emme, M. (2007). Critical issues in conducting research with immigrant children. Diaspora, Indigenous, and Minority Education, 1(3), 83-107.

Lampert, A., \& Gray, T. (2008). The Essential P. K. Page/ selected by Arlene Lampert and Théa Gray. Erin, ON: The Porcupine’s Quill.

Lundy, L., McEvoy, L., \& Byrne, B. (2011). Working with young children as co-researchers: An approach informed by the United Nations Convention on the Rights of the Child. Early Education and Development, 22(5), 714-736.

Mac Naughton, G., Rolfe, S. A., \& Siraj-Blatchford, I. (2010). Doing early childhood research: International perspectives on theory and practice. Berkshire, UK: Open University Press.

Magilvy, J. K., \& Thomas, E. (2009). A first qualitative project: Qualitative descriptive design for novice researchers. Journal for Specialists in Pediatric Nursing, 14(4), 298-300.

Matthews, S. H. (2007). A window on the "new" sociology of childhood. Sociology Compass, l(1), 322-334.

Moules, T., \& O’Brien, N. (2012). Participation in perspective: Reflections from research projects. Nurse Researcher, 19(2), 17-22.

Nutbrown, C. (2011). Naked by the pool? Blurring the image? Ethical issues in the portrayal of young children in arts-based educational research. Qualitative Inquiry, 17(1), 3-14. 
Office of the High Commissioner for Human Rights. (2005). General Comment No. 7. Implementing child rights in early childhood. Retrieved on November 30, 2012 from http://www.ohchr.org/english/bodies/crc/docs/AdvanceVersions/GeneralComment7Rev1. pdf

Pascal, C., \& Bertram, T. (2009). Listening to young citizens: The struggle to make real a participatory paradigm in research with young children. European Early Childhood Education Research Journal, 17(2), 249-262.

Phelan, S. K., \& Kinsella, E. A. (2013). Picture this...safety, dignity, and voice - Ethical research with children: Practical considerations for the reflexive researcher. Qualitative Inquiry, 19(2), 81-90.

Pierce, C. M., \& Allen, G. B. (1975). Childism. Psychiatric Annals, 5(7), 15-24.

Powell, M. A., \& Smith, A. B. (2009). Children's participation rights in research. Childhood, $16(1), 124-142$.

Prigogine, I. (1980). From being to becoming: Time and complexity in the physical sciences. San Francisco, CA: W. H. Freeman.

Punch, S. (2002). Research with children: The same or different from research with adults? Childhood, 9(3), 321-341.

Qvortrup, J. (1997). A voice for children in statistical and social accounting: A plea for children's rights to be heard. In A. James \& A. Prout (Eds.), Constructing and Reconstructing Childhood: Contemporary Issues in the Sociological Study of Childhood, London, UK: RoutledgeFalmer.

Richardson, L. (1994). Writing: A method of inquiry. In N. K. Denzin and Y. S. Lincoln (Eds.), Handbook of qualitative research pp. 516-529. London, UK: Sage. 
Sargeant, J., \& Harcourt, D. (2012). Doing ethical research with children. Berkshire, UK: Open University Press/McGraw-Hill Education.

Sandelowski, M. (2000). Whatever happened to qualitative description? Research in Nursing \& Health, 23(4), 334-340.

Sandelowski, M. (2010). What's in a name? Qualitative description revisited. Research in Nursing \& Health, 33(1), 77-84.

Spyrou, S. (2011). The limits of children's voices: From authenticity to critical reflexive representation. Childhood 18(2), 151-165.

Thomson, F. (2007). Are methodologies for children keeping them in their place? Children's Geographies, 5(3), 207-218

Tangen, R. (2008). Listening to children's voices in educational research: some theoretical and methodological problems. European Journal of Special Needs Education, 23(2), 157166.

UN General Assembly (1989). Convention on the Rights of the Child. Treaty Series, 1577.

UNICEF, (2006). A world fit for children. New York, NY: UNICEF.

Uprichard, E. (2008). Children as 'being and becomings': Children, childhood and temporality. Children \& Society, 22(4), 303-313.

Uprichard, E. (2010). Questioning research with children: Discrepancy between theory and practice? Children \& Society, 24(1), 3-13.

Wall, J. (2010). Ethics in the Light of Childhood. Washington, D.C.: Georgetown University Press. 
Warin, J. (2011). Ethical mindfulness and reflexivity: Managing a research relationship with children and young people in a 14-year qualitative longitudinal research (QLR) Study. Qualitative Inquiry, 17(4), 805-814.

Wells, K. (2009). Childhood in a global perspective. Cambridge, UK: Polity Press.

Whiting, L. (2009). Involving children in research. Paediatric Nursing, 21(5), 32-36.

Woodhead, M. (2005). Early childhood development: A question of rights. International Journal of Early Childhood, 37(3), 79-98.

Woodhead, M., \& Faulkner, D. (2008). Subjects, objects or participants? Dilemmas of psychological research with children. In P. H. Christensen \& A. James (Eds.), Research with children: Perspectives and practices (pp. 10-39). New York, NY: Routledge.

Zeldin, W. (2013). Children's rights: International laws. Retrieved from http://www.loc.gov/law/help/child-rights/internationallaw.php\#global\%20International\%20Documentation 